IZA DP No. 7047

The Minimum Wage Affects Them All: Evidence on Employment Spillovers in the Roofing Sector

Bodo Aretz

Melanie Arntz

Terry Gregory

November 2012 


\title{
The Minimum Wage Affects Them All: Evidence on Employment Spillovers in the Roofing Sector
}

\author{
Bodo Aretz \\ ZEW Mannheim and IZA \\ Melanie Arntz \\ ZEW Mannheim and University of Heidelberg \\ Terry Gregory \\ ZEW Mannheim
}

\author{
Discussion Paper No. 7047 \\ November 2012
}

\author{
IZA \\ P.O. Box 7240 \\ 53072 Bonn \\ Germany \\ Phone: +49-228-3894-0 \\ Fax: +49-228-3894-180 \\ E-mail: iza@iza.org
}

\begin{abstract}
Any opinions expressed here are those of the author(s) and not those of IZA. Research published in this series may include views on policy, but the institute itself takes no institutional policy positions. The IZA research network is committed to the IZA Guiding Principles of Research Integrity.

The Institute for the Study of Labor (IZA) in Bonn is a local and virtual international research center and a place of communication between science, politics and business. IZA is an independent nonprofit organization supported by Deutsche Post Foundation. The center is associated with the University of Bonn and offers a stimulating research environment through its international network, workshops and conferences, data service, project support, research visits and doctoral program. IZA engages in (i) original and internationally competitive research in all fields of labor economics, (ii) development of policy concepts, and (iii) dissemination of research results and concepts to the interested public.
\end{abstract}

IZA Discussion Papers often represent preliminary work and are circulated to encourage discussion. Citation of such a paper should account for its provisional character. A revised version may be available directly from the author. 
IZA Discussion Paper No. 7047

November 2012

\section{ABSTRACT \\ The Minimum Wage Affects Them All: Evidence on Employment Spillovers in the Roofing Sector}

This paper contributes to the sparse literature on employment spillovers on minimum wages by exploiting the minimum wage introduction and subsequent increases in the German roofing sector that gave rise to an internationally unprecedented hard bite of a minimum wage. We look at the chances of remaining employed in the roofing sector for workers with and without a binding minimum wage and use the plumbing sector that is not subject to a minimum wage as a suitable benchmark sector. By estimating the counterfactual wage that plumbers would receive in the roofing sector given their characteristics, we are able to identify employment effects along the entire wage distribution. The results indicate that the chances for roofers to remain employed in the sector in eastern Germany deteriorated along the entire wage distribution. Such employment spillovers to workers without a binding minimum wage may result from scale effects and/or capital-labour substitution.

JEL Classification: J38, J21, J23

Keywords: $\quad$ minimum wage, Germany, capital-labour substitution, labour-labour substitution, scale effect

Corresponding author:

Bodo Aretz

Centre for European Economic Research (ZEW)

Department of Labor Economics, Human Resources and Social Policy

L7 1

68161 Mannheim

Germany

E-mail: aretz@zew.de

\footnotetext{
"We thank for financial support through the grant "Minimum wage effects in the roofing sector" by the ZEW Sponsors' Association for Science and Practice. We would further like to thank Stephan Dlugosz and the participants of the "Workshop on Minimum Wage Research" in Mannheim for fruitful discussions. The project also profited from a preceding evaluation of minimum wage effects in the German roofing sector that was financed by the German Federal Ministry of Labour and Social Affairs (BMAS). The authors are responsible for all results and conclusions derived in this study. They do not necessarily reflect the views of the BMAS. All remaining errors are our sole responsibility.
} 


\section{Introduction}

Most minimum wage research focusses on the average employment effect that minimum wages exert on workers with a binding minimum wage, i.e. workers whose wage has to be raised in order to comply with the minimum wage level. In a competitive labour market with a heterogenous workforce and an elastic product demand, for example, workers for whom the minimum wage raises labour costs are expected to experience negative employment outcomes: (Brown 1999). However, depending on the production technology, the minimum wage (in short MW) may also affect workers for whom the minimum wage is not binding, see e.g. Neumark and Wascher (2008). If workers with and without a binding minimum wage are complements, a negative scale effect that results from a reduced product demand negatively affects all workers' employment chances. If the two types of workers are substitutes, the MW may raise the demand for workers who earn a wage above the MW, thereby counteracting the negative scale effect by a positive substitution effect. In this case, we may observe negative employment effects for workers with a binding MW and even positive employment effects for workers with a non-binding MW. Moreover, profit-maximising firms may potentially substitute capital for the relatively more expensive labour input, thereby inducing an additional employment decline for all workers who are substitutable by capital. In this latter case, a firm might, in fact, lay off the poorest performers of each type of worker and reduce employment also among workers with a non-binding MW.

The existing literature mainly discusses employment spillovers, i.e. indirect employment effects for workers with a non-binding minimum wage, as a potential source of bias. Linneman (1982), Currie and Fallick (1996), Abowd et al. (2000), and Neumark et al. (2000), e.g., identify the average employment effect on workers with a binding MW by comparing workers with and without a binding MW. Attempts to estimate substitution effects between workers tend to focus on the elasticity of substitution between skill or age groups rather than between workers with and without a binding MW $2^{2}$ The only study

\footnotetext{
${ }^{1}$ In case of a monopsonistic labour market that allows employers to set wages below the equilibrium wage, a minimum wage may instead induce positive or zero employment effects.

${ }^{2}$ See e.g. Neumark and Wascher (1995) for the substitution between age groups, Abowd and Kil-
} 
that we are aware of that focuses on employment effects along the wage distribution is by Neumark et al. (2004). They report evidence for a negative employment spillover for workers with a wage just above the minimum level.

The aim of this paper is to contribute to the sparse literature on employment spillovers by investigating employment effects along the entire wage distribution. In particular, our contribution is threefold. First of all, we are able to analyse employment effects in a context where the minimum wage bites very hard: the roofing sector in Germany. Its minimum wage was introduced in 1997 and was subsequently raised several times. With a Kaitz Index, i.e. the ratio of the minimum wage level and the median wage, that is around 1 in eastern Germany, the bite has to be considered exceptional even by international standards (Machin et al. 2003, Dolton and Bondibene 2011). The German roofing sector, thus, is an ideal setting to study employment effects along the entire wage distribution since its bite is likely to render indirect employment effects for workers above the minimum wage.

Secondly, we are able to exploit a natural experiment since, for institutional reasons, the minimum wage was introduced only in parts of the construction sector including the roofing sector. Uncovered, yet comparable, sub-sectors may thus serve as a benchmark for the counterfactual development in the roofing sector in order to derive the average treatment effect on the treated (ATT) with respect to the chances of remaining employed in the roofing sector. Since the entire construction sector experienced a dramatic decline in demand after the end of the unification boom in the mid 1990s that almost halved the workforce in Eastern Germany, this is a highly relevant employment outcome.

Thirdly, we contrast the ATT from an intersectoral comparison with an ATT derived from a comparison of workers with and without a binding MW within the roofing sector. Under a number of identifying assumptions, a deviation between these ATTs may hint at employment spillovers within the roofing sector. In order to make such spillovers visible, we then combine both identification strategies. For this purpose, we estimate the counterfactual wage that workers of the control sector would receive in the roofing ingsworth (1981), and Neumark and Wascher (1994) for the substitution between skill groups, and Hsing (2000) for substitution between part-time and full-time work. 
sector given their characteristics. This enables a comparison of workers with and without a binding MW across sectors and also allows for estimating the employment effects along the entire wage distribution.

Finally, we make use of two administrative linked-employer-employee panels one of which contains the full sample of workers in the roofing sector over the observation period of interest. Hence, we are able to take account of unobserved heterogeneity at the individual level, which may be relevant if employers mainly substitute workers along unobservable skills as was suggested by Fairris and Bujanda (2008). Our paper, thus, yields much broader insights into the employment effects of minimum wages than most previous studies.

The findings indicate that the chances to remain employed in the roofing sector have deteriorated due to the minimum wage introduction, especially in eastern Germany where the bite of the MW was particularly hard. However, the impact suggested by comparing workers with and without a binding MW appears to be underestimated compared to the intersectoral comparison, thus hinting at employment spillovers. An intersectoral comparison suggests negative employment outcomes for east German workers along the entire wage distribution. According to personal interviews with sector insiders, capitallabour substitution rather than scale effects drive this finding. Our results highlight the need for a broader perspective on the employment impact of minimum wages and also put doubts on any attempt to identify employment effects of minimum wages by comparing workers with and without a binding MW within a covered sector.

The paper is structured as follows. Section 2 contains information on the German roofing sector, the introduction of the minimum wage and discusses some expectations for the empirical estimations given its market structure. Section 3 describes the data basis before Section 4 discusses the bite of the minimum wage. Section 5 describes the general difference-in-differences estimation framework for the identification of employment effects that is applied to different treatment and control groups in Sections 6 and 7 . Section 8 concludes. 


\section{The German Roofing Sector}

Market structure. The goods and services that are provided by the roofing sector encompass the roofing of new buildings as well as the mending of old roofs. Roofing is a traditional craft in Germany requiring a master craftsman's diploma in order to start a business $\mathrm{H}^{3}$ These traditional roofing companies usually employ less than ten employees and provide their services regionally and mainly to private home owners whose demand may be rather inelastic given the few available and mainly illegal substitutes such as moonlighting. In a survey among 250 roofing companies in 2011, more than three quarters of all companies considered quality rather than prices to be the main dimension of competition (Aretz et al. 2011). For those companies with more than 30 employees, which constitute less than 10\%, however, price competition may be more relevant since they tend to work for public contractors and are active beyond regional boundaries. $4^{4}$

Moreover, in contrast to most sectors that have been studied extensively in the MW literature, the roofing sector has a rather high level of qualification and is not very labour intensive. More than $95 \%$ of all workers work fulltime, and a relatively high share of around three quarters has at least a vocational training degree $5^{5}$ Moreover, labour costs account for less than $40 \%$ of total costs only (Cost Structure Survey 2001), and technical advances regarding materials and roofing techniques appear to be quite important as reported by roofing companies in a number of qualitative interviews..$^{6}$

Business cycle. The entire construction sector experienced a boom period in the early 1990s due to German reunification but began to shrink from the mid 1990s on, see Figure 1. In eastern Germany, this post-unification downturn was much more dramatic than in western Germany and reduced the construction sector's revenues in the subsequent

\footnotetext{
${ }^{3}$ As an exception, it is not required to hold such a diploma if someone works as an itinerant worker. Such workers tend to work alone and mainly provide mending services only.

${ }^{4}$ Information on company size is based on the BA data (see Section 3 for details).

${ }^{5}$ The part-time information is taken from the Cost Structure Survey for 2001 (Kostenstrukturerhebung), which is released by the German Statistical Office. The share of qualified workers is calculated based on the BA data (see Section 3 for details).

${ }^{6}$ Ten qualitative interviews with roofing companies and four additional interviews with representatives of the trade union and the employer's association were conducted within a report prepared for the Federal Ministry of Labour and Social Affairs, see Aretz et al. (2011) for details.
} 
years by more than half. After 2004, all construction sectors reinstalled revenue levels in western Germany similar to the early 1990s, while the recovery in eastern Germany was rather marginal. Compared with structural engineering, the roofing sector and other subconstruction sectors such as plumbing, glazing and painting services experienced a less dramatic decline in the demand for their services in the mid 1990s and a faster recovery after 2004. The demand for sub-construction work hinges on the demand for new buildings as well as the age structure of the existing stock of houses with the latter apparently having a smoothing impact on the business cycle compared to structural engineering.

Figure 1: Overall revenues in western and eastern Germany by sector, 1994 - 2009
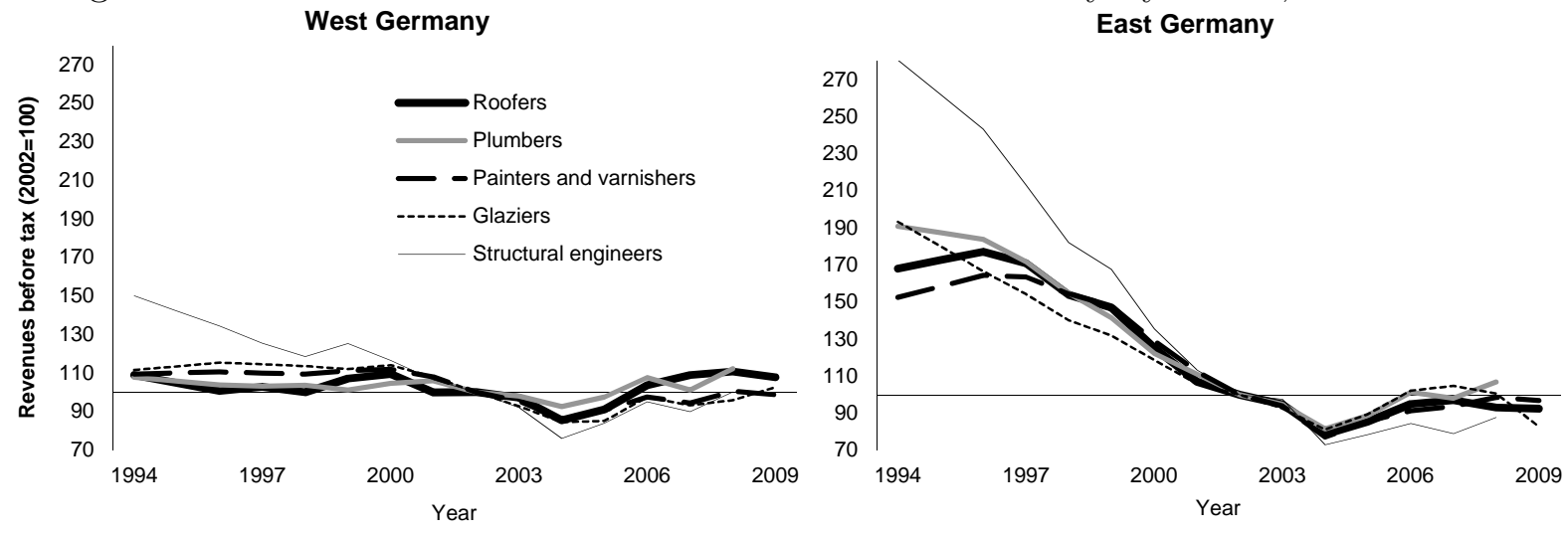

Source: Revenue tax statistics, German Federal Statistical Office

Moreover, sub-construction sectors broadened their portfolio during the last years, thereby stabilising the demand for their services. In particular, roofing companies are increasingly involved in the assembling of photovoltaic cells as well as the ex post insulation of old roofs.7 The plumbers and, to a lesser extent, glaziers and painters also benefited from this development. At least in western Germany, this has presumably contributed to a faster recovery in the roofing and the plumbing sector compared to other sub-construction sector and structural engineering.

Minimum wage regulations. Apart from shrinking demand, additional pressures in the mid 1990s stemmed from the introduction of a free movement of labour that allowed eastern European firms to send workers to German construction sites while paying home

\footnotetext{
${ }^{7}$ Both of these developments have been boosted by government initiatives for subsidising solar energy generation since 2000 (Erneuerbare-Energien-Gesetz) and energy-saving renovations since 2002 (Energetische Gebäudesanierung).
} 
country wages. In order to protect German workers, legally binding minimum wages that had to be paid to all workers on German construction sites irrespective of the origin of their contract were introduced in the structural engineering and some sub-construction sectors. Since minimum wages are negotiated separately for certain sub-divisions of the construction sector, not all sub-divisions agreed on minimum wage regulation, resulting in a coexistence of quite comparable sectors with a legally binding minimum wage (e.g. structural engineering and roofing sector since 1997; painting sector since 2003) and sectors such as glazing and plumbing services that are not subject to a legally binding minimum wage until now. Hence, these sectors may potentially serve as a benchmark for the counterfactual development in the roofing sector in the absence of a legally binding minimum wage.

The minimum wage in the roofing sector applies to all blue-collar workers of any roofing company or roofing branch within a larger company who are at least 18 years of age, who are not an apprentice and who are not working as a custodial worker. Thus, all white-collar workers such as office clerks as well as certain parts of the blue-collar workforce are exempted from the minimum wage regulation. Introduced in October 1997, the minimum wage was subsequently raised several times and was even interrupted by short periods without any legally binding minimum wages, see Figure 2, These interruptions reflect the fact that the minimum wage is negotiated between the responsible trade union ( IG Bau) and the association of employers in the roofing sector (Zentralverband des Deutschen Dachdeckerhandwerks) as a part of the general collective bargaining agreement. When these agreements expire, there may be short interruptions before a new agreement is reached. Because the continuation of a minimum wage was not subject to any debate since its introduction, roofing companies could, however, expect a new minimum wage agreement, rendering any behavioural adjustments during these interruptions very unlikely. Moreover, minimum wages were harmonised between western and eastern Germany in 2003 despite wages in western Germany exceeding wages in eastern Germany by about $25 \%$. This results in an extremely hard bite of the minimum wage in eastern Germany as we will see in Section 4. 
Figure 2: Minimum wage level in the German roofing sector by region, 1995-2010

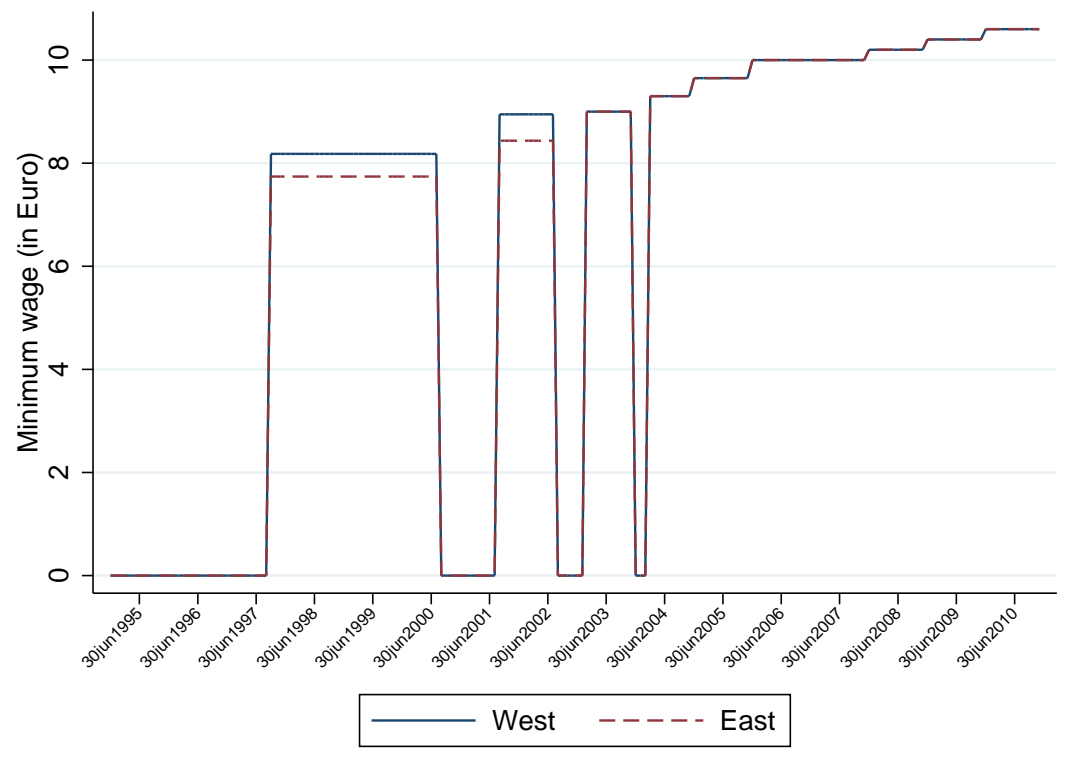

Taking all this evidence together, the roofing sector's market structure suggests a rather limited impact of minimum wages on employment given its limited labour intensity, the ability of roofing companies to at least absorb some of additional costs by raising prices and the fact that technical advances and increases in productivity offer options for cushioning rising labour costs. At the same time, however, the lower wage floor was fixed on a rather high level (see also section 4), particularly in eastern Germany, thus rendering employment effects likely. Moreover, changes in relative input prices may create incentives for substituting labour by capital and/or less skilled by skilled workers. Finally, the minimum wage in the roofing sector was introduced during a period of economic downturn and a shrinking market size. This strongly reduced the sector's workforce (see Appendix A), although the number of companies even slightly increased at the same time as the share of single-person companies jumped from $8 \%$ in 1995 to $23 \%$ in 2010 . With the number of unemployed workers with sector-specific human capital queuing for jobs on a rise, the bargaining power of those still working in the sector may have come under pressure. 


\section{Administrative Linked Employer-Employee Data}

For our analysis, we are able to exploit two administrative linked employer-employee panel data sets: (1) data that is collected by the central pay office of the roofing sector (Lohnausgleichskasse, LAK), in short the LAK data, and (2) data that is collected by the Federal Labour Agency (Bundesagentur für Arbeit, BA) for all employees that are subject to social insurance contributions, in short the BA data.

\subsection{LAK Data}

In order to balance out the seasonal fluctuation of the sector, all roofing companies have to pay an insurance premium to the LAK that is related to the total payroll of their blue-collar workers. Therefore, they are obliged to give a monthly record to the central pay office of the roofing sector. For our analysis, we have access to the full sample of blue-collar workers on a monthly basis for the years 1995 to 2010, thus covering both the pre- and post-minimum wage period. Information on monthly working hours and monthly gross wage allows for calculating the hourly gross wage. Between October and April, however, reported working hours need not match the true working hours because of special regulations for cushioning the seasonal character of the sector's activities. Hence, we use the June information for the analysis based on the LAK data in order to avoid such distortions and to ensure the comparability of the analysis with the BA data (see below).

The data contains additional information only on sex and age of the workers. Since we do not know whether someone is an apprentice or working as a custodial worker, who are both exempted from the minimum wage regulation, we are not able to exactly identify all covered workers. Since most custodial workers are female, however, and the share of females among covered roofers is less than $2 \%$ according to the BA data, we exclude women from the LAK sample. We also exclude all workers below the age of 19 and assume that this also eliminates most uncovered apprentices. Our sample, thus, differs from the exact coverage by missing some covered women and including some uncovered 
apprentices in the sample. Overall, we observe a total of 1,094,609 observations between 1995 and 2010 that stem from 217,779 individuals in 22,879 firms. Note that we are able to calculate some firm level information such as average gross pay, average firm size and average age of the company's workforce that we can use in addition to the individual information.

\subsection{BA Data}

A major disadvantage of the LAK data is that it is only available for the roofing sector, thus precluding any identification strategy that rests upon inter-sector comparisons. Such an alternative identification strategy, however, becomes available based on the BA data since it includes information for $75 \%$ of all companies in the roofing sector as well as sub-samples of companies in other sub-construction sectors such as painting, plumbing and glazing services for the observation period from 1994 to 2008.8 For all individuals who are subject to social insurance contributions and work in one of these companies on June 30th, the data contains the corresponding period of continued employment in that company within the calender year that overlaps June 30th.9 Thus, the longest spell encompasses the full calender year, while the shortest employment spell would be an employment period of one day on June 30th only.

For each employment spell, we have information on age, sex, educational background, the gross daily wage, occupation, and occupational status. Thus, the data allows for identifying covered individuals quite precisely. In particular, we are able to exclude custodial workers, apprentices and white-collar workers as well as underage workers 10 Overall, the sample consists of 791,910 observations in the roofing sector that stem from 172,257 covered roofers in 17,186 roofing firms and 1,557,661 observations by 354,834 workers in

\footnotetext{
${ }^{8}$ This information is taken from the Betriebshistorikdatei, a data set that aggregates the individual data that is collected by the BA to the firm level, see Hethey-Maier and Seth (2010) for details on the data.

${ }^{9}$ This information is taken from the employee record of the BA (Beschäftigtenmeldungen), see e.g. Drews (2008) for details.

${ }^{10} \mathrm{We}$ also exclude workers with a minor employment which is defined as earning below the social insurance contribution threshold of $400 €$ per month because these workers are included in the data only after 1998. For comparability reasons, we also dropped such workers in the LAK data.
} 
35,250 firms from other sub-construction sectors who fulfill the same criteria.

Since the data only distinguishes between full-time and part-time workers and includes information on daily gross wages only, the main restriction of the BA data refers to the corresponding lack of information on hourly gross wages. As a remedy, we impute the hourly gross wage by estimating the observed hourly gross wage in the LAK data as a function of explanatory variables that are available in both data sets. For this purpose, we first adjust the LAK data to have a similar data structure as the BA data by creating employment spells for each individual who has worked on June 30th. For these spells, both data sets provide information on or allow for computing the length of the spell, the beginning of the spell, the daily gross wage, dummies for part-time or full-time employment, individual information on sex and age as well as a number of firm-level information such as firm size, workforce composition, and average gross daily wage. Using all these explanatory variables and allowing for additional heterogeneity by estimating the wage model separately for each year, eastern and western Germany as well as for workers of different quintiles of the daily gross wage distribution, we are able to explain $88 \%$ of the variation in hourly gross wages in the LAK data. We then use these estimates for predicting the hourly wage in the BA data. The quality of this imputation not only hinges on the $R^{2}$ of the wage estimation, but also depends on the comparability of the LAK and the BA sample and explanatory variables. Appendix B shows that the imputed and observed wage distribution are very comparable. As a result, the average predicted mean wage for full-time workers of $13.26 €$ and $9.94 €$ in the BA data in western and eastern Germany, respectively, comes very close to the observed average wage in the LAK data with $13.22 €$ for western Germany and $9.85 €$ for eastern Germany.

\section{The Minimum Wage and Its Bite}

Table 1 displays several indicators of the bite of the minimum wage (MW) for the June preceding the introduction of a new MW regulation within the next year. In particular, we look at the share of covered workers for whom the upcoming MW is binding due to 
earning a wage below the minimum in the June preceding the new MW regulation 11 We also show the average wage increase these workers would have to receive in case of full compliance with the upcoming MW. This individual wage gap for a worker $i$ with a binding MW in period $t$ is thereby defined as follows:

$$
\text { wage } \operatorname{gap}_{i t}=\frac{M W_{i, t+1}-w_{i t}}{w_{i t}}
$$

where $w_{i t}$ represents the workers hourly wage and $M W_{i, t+1}$ the upcoming MW. We contrast this wage gap to their actual wage increase within the next year and the actual wage increase during the same time period among workers for whom the MW was not binding. We complement this information by the Kaitz-Index, i.e. the ratio between the MW level and the median wage in the sector. Note that the indicators may slightly underestimate the bite of the MW due to the fact that the hourly wage may contain overtime compensation that is not subject to the MW ${ }^{12}$

The indicators based on the LAK data allow for several interesting insights. First of all, the share of covered workers for whom the MW was binding by the time of its introduction was as low as $1.3 \%$ in western Germany compared to $12.5 \%$ in eastern Germany. While this share rose up to $5 \%$ in western Germany until 2008, around $50 \%$ of all eastern workers earned below the upcoming MW at that time, a share that clearly exceeds the impact level that Machin et al. (2003) considered a hard biting MW. This extreme bite results from the introduction of a common MW level in both parts of the country in 2002. Since then, the MW level approximately corresponds to the median wage in eastern Germany so that the Kaitz-Index ranges around 100\%. Even in western Germany, the Kaitz-Index still ranges between two thirds and three quarters of the median wage. Compared to Dolton and Bondibene (2011), who find the Kaitz-Index to range between $30 \%$ and $70 \%$ in a survey among $22 \mathrm{OECD}$ countries, the bite of the MW in the roofing sector, at least

\footnotetext{
${ }^{11}$ We do not adjust for nominal wage changes between the two dates of comparison because the intermediate time span is mostly quite short.

${ }^{12}$ On average, overtime hours account for $6 \%$ of the working hours in June and, thus, may lead to an estimated hourly wage that is up to $1.6 \%$ too high depending on the applied overtime compensation scheme ranging from no additional compensation to a markup of $25 \%$. Since we do not know which scheme is applied, we left the data uncorrected as the resulting imprecision appears to be rather marginal.
} 
Table 1: Indicators of the minimum wage bite measured in June prior to the next MW regulation, LAK and BA data

\begin{tabular}{|c|c|c|c|c|c|c|c|}
\hline $\begin{array}{l}\text { New MW regulation } \\
\text { takes effect on }\end{array}$ & $\begin{array}{c}\text { MW } \\
\text { (in Euro) }\end{array}$ & $\begin{array}{c}\text { Share } \\
\text { (in \%) } \\
\text { LAK }\end{array}$ & $\begin{array}{c}\text { Share } \\
\text { (in \%) } \\
\text { BA }\end{array}$ & $\begin{array}{l}\text { s with a bin } \\
\text { Yes } \\
\text { Wage gap } \\
\text { (in \%) } \\
\text { LAK }\end{array}$ & $\begin{array}{c}\operatorname{ling} \text { MW? } \\
\Delta \text { Wage }^{\mathrm{b}} \\
(\text { in } \%) \\
\text { LAK }\end{array}$ & $\begin{array}{c}\text { No } \\
\Delta \text { Wage }^{\mathrm{b}} \\
(\text { in } \%) \\
\text { LAK }\end{array}$ & $\begin{array}{c}\text { Kaitz } \\
\text { Index } \\
\text { LAK }\end{array}$ \\
\hline \multicolumn{8}{|l|}{ Western Germany } \\
\hline 01.10 .97 & 8.2 & 1.3 & 2.4 & 11.0 & 7.2 & 2.3 & 64.7 \\
\hline 01.09 .01 & 9.0 & 1.5 & 3.9 & 8.7 & 6.8 & 1.4 & 67.2 \\
\hline 01.03 .03 & 9.0 & 1.5 & 3.4 & 8.9 & 6.0 & 2.4 & 67.2 \\
\hline 01.04 .04 & 9.3 & 2.2 & 4.8 & 8.1 & 5.7 & 1.4 & 68.4 \\
\hline 01.05 .05 & 9.7 & 2.9 & 5.8 & 8.5 & 4.9 & 0.6 & 70.3 \\
\hline 01.01 .06 & 10.0 & 4.4 & 6.9 & 7.9 & 4.9 & 1.1 & 72.6 \\
\hline 01.01 .07 & 10.0 & 4.6 & 7.5 & 8.1 & 6.7 & 3.2 & 72.7 \\
\hline 01.01 .08 & 10.2 & 5.4 & 8.2 & 6.7 & 5.3 & 2.2 & 73.1 \\
\hline 01.01 .09 & 10.4 & 4.9 & 7.5 & 6.6 & 8.1 & 3.0 & 73.4 \\
\hline \multicolumn{8}{|l|}{ Eastern Germany } \\
\hline 01.10 .97 & 7.7 & 12.5 & 11.5 & 9.7 & 6.7 & 0.0 & 82.0 \\
\hline 01.09 .01 & 8.4 & 14.2 & 12.0 & 3.9 & 4.6 & 0.6 & 89.2 \\
\hline 01.03 .03 & 9.0 & 34.1 & 23.3 & 4.2 & 4.1 & 0.1 & 95.0 \\
\hline 01.04 .04 & 9.3 & 44.1 & 28.7 & 3.8 & 4.1 & 0.3 & 97.9 \\
\hline 01.05 .05 & 9.7 & 46.9 & 33.5 & 4.3 & 4.0 & 0.1 & 99.2 \\
\hline 01.01 .06 & 10.0 & 55.5 & 40.8 & 4.1 & 4.0 & 0.1 & 100.2 \\
\hline 01.01 .07 & 10.0 & 45.5 & 28.1 & 1.6 & 1.9 & 0.9 & 99.6 \\
\hline 01.01 .08 & 10.2 & 53.5 & 32.1 & 2.6 & 3.3 & 1.3 & 100.7 \\
\hline 01.01 .09 & 10.4 & 50.0 & 28.9 & 2.4 & 3.3 & 0.7 & 99.9 \\
\hline
\end{tabular}

a Wage gap refers to equation (1)

b $\Delta$ wage corresponds to the actual observed percentage wage change $\left(w_{i t+1}-w_{i t}\right) / w_{i t}$ between the June preceding and the June following the new MW regulation.

in eastern Germany, is thus extremely hard.

We also observe that the MW has been effective, i.e. actual wage increases among workers with a binding MW exceeded the wage increases among workers for whom the MW was not binding. While the change in the west German wage distribution is rather marginal, the wage compression in eastern Germany results in a huge spike of workers whose wages range around the MW level, see Figure 3. Finally, note that despite these actual increases, they still fall short of the increases workers would have had to receive in case of full compliance, especially in western Germany during the initial years after the MW introduction. The improved compliance with the MW regulation during the last years might be due to stronger controls after 2006 according to interviews that we 
Figure 3: Kernel densities of hourly gross wages in eastern and western Germany, 1995 and 2008, LAK data

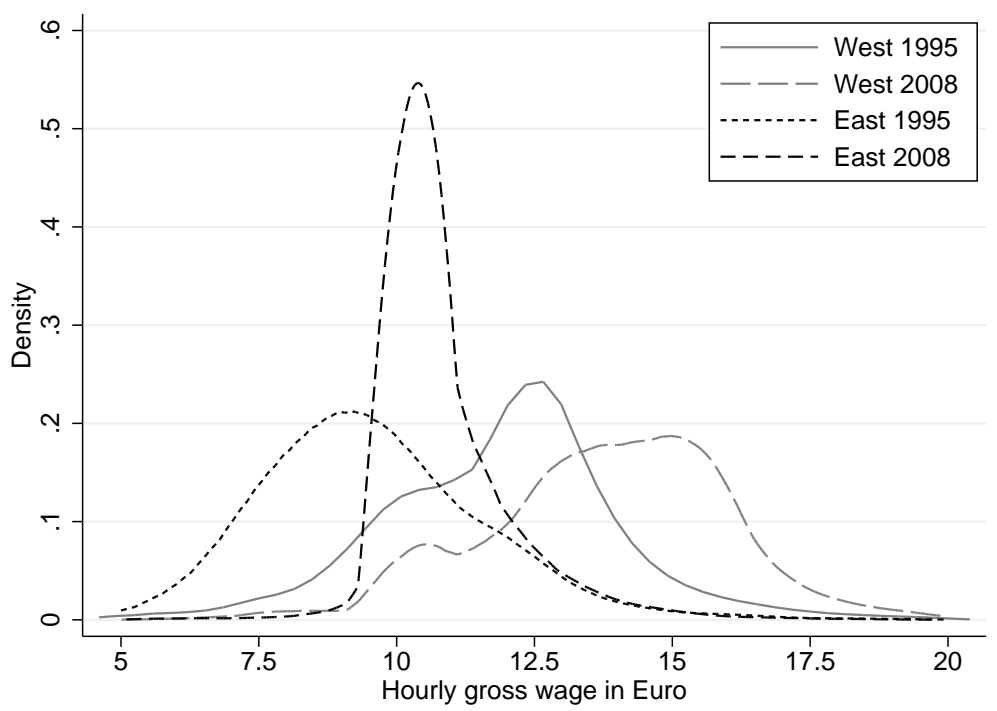

conducted with sector insiders.

Table 1 also contrasts the share of workers with a binding MW based in the LAK data to the corresponding share based on the imputation in the BA data. In contrast to the LAK data, however, the share of workers with a binding MW follows a probabilistic concept because we do not only impute the mean wage prediction for each individual but also the corresponding distribution that results from the unexplained variance and the variance of the estimated parameters. Assuming this distribution to be normally distributed, we are then able to calculate the probability that the wage of a worker falls below the MW level which we denote by $P_{M W}$. For the BA data, Table 1 thus reports the average predicted probability of being affected by a binding MW among all covered workers.

As we can see, the resulting share of workers with a binding MW resembles the LAK patterns but differs in levels, especially for eastern Germany in the last years. In fact, imputing the probability of being affected by a binding MW in the LAK data, gave very similar deviations to the observed share of workers with a binding MW. Hence, it is apparently the extreme wage compression that leads to the asymmetric form of the wage distribution in Figure 3 and, thus, to a systematic underestimation of the share of workers with a binding MW in eastern Germany, see Appendix $\mathrm{C}$ for further explanation. 
Despite the large bite of the minimum wage, especially demonstrated by the high wage compression in Eastern Germany, the overall labour cost burden is still modest for two reasons. First, even in the case of full compliance with respect to the minimum wage regulations, total labour costs only increased by $1 \%$ in Western Germany and $2.5 \%$ in Eastern Germany on average during the observed time period. Second, labour costs amount to less than $40 \%$ of total costs, so that the change in average total costs varies across time between $0.2-0.5 \%$ in Western Germany and $0.3-0.8 \%$ in Eastern Germany. However, despite the low impact on total costs on average, some firms may well be affected more strongly. Moreover, the cost burden may cumulate over time due to the gradual increase in the minimum wage level.

Finally, it is worth mentioning that individuals with a binding MW clearly differ between western and eastern Germany. While the average worker with a binding MW in eastern Germany does not differ much from an average worker without a binding MW, the average worker with a binding MW in western Germany rather corresponds to a marginal worker with below average human capital, short tenure and part-time employment in firms with a skill and wage level below average, see Table 2 .

Table 2: Characteristics of workers in western and eastern Germany by binding status, BA data 1995-2008

\begin{tabular}{|c|c|c|c|c|}
\hline & Western & Germany & Eastern & Germany \\
\hline MW for workers is binding? & Yes & No & Yes & No \\
\hline \multicolumn{5}{|l|}{ Individual characteristics } \\
\hline Worker with voc. training deg. (in \%) & 24.1 & 67.2 & 70.2 & 80.4 \\
\hline Workers without voc. training (in \%) & 34.5 & 31.1 & 25.2 & 19.0 \\
\hline Part-time workers (in \%) & 41.3 & 1.7 & 4.6 & 0.5 \\
\hline Previous work exp. in sector (in years) & 2.2 & 4.3 & 2.9 & 3.6 \\
\hline Previous tenure in firm (in years) & 1.9 & 3.7 & 2.2 & 3.0 \\
\hline \multicolumn{5}{|l|}{ Firm characteristics } \\
\hline Average firm size & 4.0 & 6.2 & 5.7 & 7.8 \\
\hline Firm's share of skilled workers (in \%) & 63.1 & 83.1 & 79.9 & 82.2 \\
\hline Firm's mean daily gross wage (in Euro) & 51.78 & 72.33 & 50.43 & 56.08 \\
\hline Number of observations & 15,523 & 485,640 & 39,960 & 196,981 \\
\hline
\end{tabular}

Note: Workers with $P_{M W}>0.5$ are considered to be bound by the MW. 


\section{General Framework for the Identification of Em- ployment Effects}

Since the minimum wage was introduced for the entire sector at the same time, a strategy for the identification of the minimum wage impact cannot rest on regional variation as has been done in many US studies (among others Dube et al. 2007 and 2010 and Card and Krueger 1994 and 2000). Exploiting the existing variation in the minimum wage level between eastern and western Germany in the mid 1990s is also not advisable since the business cycle after the reunification boom differed between both parts of the country, see Figure 1

Thus, there are mainly two potential approaches available for the identification of employment effects. Either one exploits the variation in treatment intensity within the roofing sector by comparing workers with and without a binding MW, or one uses a subconstruction sector that is not covered by a minimum wage regulation but is as similar as possible to the roofing sector. To see why and under which assumptions these control groups allow for an estimation of the average treatment effect on the treated (ATT), let $e_{i t}$ denote the employment status in period $t$ for an individual $i$. In particular, let $e_{i t+1}=1$ in case of being employed in the same sector as in the previous period and $e_{i t+1}=0$ otherwise, an outcome measure that we are able to observe in both the LAK and the BA data.

This outcome measure is of main interest in a market context that is dominated by a shrinking market size and a corresponding reduction in employment since the mid 1990s, compare Appendix A. The question of whether someone was able to keep his job in this market context given the additional cost pressures of the minimum wage is of main concern. Note, however, that this outcome should not be equated with effects on the total employment in the roofing sector. As an example, additional market entries by single person companies are not captured by this employment outcome.

With this outcome measure in mind, denote the group of treated individuals as $g_{1}$ and the group not treated as $g_{0}$. Let the minimum wage be introduced in $t^{*}$ with $t_{0}<t^{*}<t_{1}$. 
Note that all years prior to 1997 measure the ex-ante situation $t_{0}$, while observations for the ten observable years after 1997 measure the ex-post situation $t_{1}$ because the employment outcome in the following June, $e_{i t+1}$, is already influenced by the MW introduction in October 1997 for workers observed in June 1997. For the ex-post situation, we either get an estimate for $\mathbf{E}\left[e_{i t+1} \mid g_{1}, t_{1}\right]$ or $\mathbf{E}\left[e_{i t+1} \mid g_{0}, t_{1}\right]$. The average treatment effect on the treated $(\mathrm{ATT}), \theta$, can now be estimated by assuming that the difference in employment outcomes between $t_{0}$ and $t_{1}$ was the same for both groups in the absence of the treatment. Moreover, we need to assume that the treatment does not indirectly affect the control group, for example, via substitution effects. In this case, the causal impact $\theta$ is given by the difference-in-differences (DiD) estimator

$$
\mathbf{E}\left[e_{i t+1} \mid g_{1}, t_{1}\right]-\mathbf{E}\left[e_{i t+1} \mid g_{1}, t_{0}\right]-\left(\mathbf{E}\left[e_{i t+1} \mid g_{0}, t_{1}\right]-\mathbf{E}\left[e_{i t+1} \mid g_{0}, t_{0}\right]\right)=\theta
$$

In order to relax the assumption that the control group captures the counterfactual employment outcome, we can also estimate the $\mathrm{DiD}$ effect within a regression framework that controls for observable differences across both groups. Since the outcome measure calls for a non-linear analysis, we use a Logit estimation with

$$
P\left(e_{i t+1}=1\right)=\Lambda\left[\alpha_{g}+\gamma_{t}+\delta D_{i t}+\beta X_{i t}+\epsilon_{i t}\right]
$$

where $\alpha_{g}$ captures the time constant difference between both groups, $\gamma_{t}$ captures the change across time that is common to both groups, and $X$ corresponds to a set of control variables. $D_{i t}$ is the treatment indicator with $D_{i t}=1$ for individuals of group $g_{1}$ for the period $t>t^{*}$, i.e. for the treatment group after treatment has taken place, and $D_{i t}=0$ otherwise. Note that neither the coefficient for $D_{i t}$ nor its odds ratio capture the treatment effect of interest due to the non-linearity of the estimator. Following Puhani (2008), we estimate the marginal effect of $\delta$ to derive the treatment effect of interest $\theta$ by using the following formula:

$$
\theta=M E(\delta)=\Lambda\left[\alpha_{g}+\gamma_{t}+\delta D_{i t}+\beta \hat{x}\right]-\Lambda\left[\alpha_{g}+\gamma_{t}+\beta \hat{x}\right]
$$


where $\hat{x}$ indicates that we calculate the marginal effect for the average individual observed in the sample. In particular, we add covariates that may affect employment outcomes and could potentially be related to the treatment indicator such as sex, age, education, occupational status, and work experience in the sector and in the company as well as some firm characteristics such as size, the composition of the workforce, and mean wage level. By including these firm characteristics, we control for the fact that unproductive workers may be selected into less productive and thus less well-paying companies that differ with regard to employment chances irrespective of the minimum wage.

In addition, selection on unobservables may be relevant. If, for example, employers mainly dismiss the most unproductive workers for a given type of qualification and experience, not controlling for this would upward bias our estimates. Due to the longitudinal nature of our data, we can mitigate this problem by allowing for individual-specific timeconstant effects. Note, however, that one cannot calculate the marginal effect of interest for a Fixed Effects Logit Estimator because the fixed effects are not identified in this model framework (Wooldridge, 2002). Moreover, the Fixed Effects Logit Estimator only uses the sub-sample of the observations for which we observe a change in the outcome across time. This is problematic since we find evidence that the conditional sample depends on the treatment, thereby biasing the estimates. Hence, we estimate a simple linear fixed effects model, thereby avoiding the non-linear complications. We find that in most cases, only very few observations have predictions outside the plausible range. Moreover, pooled Logit and pooled OLS estimates also turned out to be quite similar. We, thus, report linear fixed effects results whenever individual fixed effects seem necessary.

\section{Average employment effects}

In this section, we apply the general framework introduced in the latter section to the intersectoral comparison (Section 6.1) and the comparison within the roofing sector (Section 6.2). As we will see, the comparison of both approaches yields first insights into possible spillover effects. In Section 7, we will then explicitly look at spillovers in the 
roofing sector by separately running the intersectoral comparison for workers with and without a binding MW as well as for workers falling in different wage deciles. This is feasible because we are able to identify comparable workers within the control sector.

\subsection{Intersectoral comparison}

Approach. A feasible control sector needs to capture the counterfactual change in employment outcomes for roofers in the absence of the minimum wage. For this to be a plausible assumption, the control sector should have a comparable market structure as well as comparable demand conditions. Among the sub-construction sectors without a legally binding minimum wage - the plumbing and the glazing sector ${ }^{13}$ - the plumbing sector is preferable for a number of reasons. According to Figure 1 the business cycle in the plumbing rather than the glazing sector resembles the business cycle in the roofing sector. In fact, for western Germany demand conditions almost follow the same path, while in eastern Germany the demand for plumbing services started to drop somewhat earlier than in the roofing sector, a deviation that we will return to in the robustness analysis.

Moreover, the plumbing sector is similar to the roofing sector with regard to important market indicators that moderate the potential impact of a minimum wage, see Table $3{ }^{14}$ In particular, roofing and plumbing companies are similarly sized in terms of both the number of employees and the revenues generated. Also, the value added is highest in the roofing sector, closely followed by the plumbing sector. Moreover, the glazing sector is more labour-intensive and invests almost twice as much per employee than the other sectors while the average gross daily wage is quite comparable across all sectors. Finally, the number of companies per one million euro of revenues in the sector, a measure of the degree of competition, is almost identical in the roofing and plumbing sector but much lower in the glazing sector, suggesting less competition.

Therefore, we consider the plumbing sector as a suitable and better benchmark for the

\footnotetext{
${ }^{13}$ The painting sector introduced a MW in 2003.

${ }^{14}$ We display the pre-minimum wage indicators for 1996 wherever it is available as the basis for judging the usefulness of a sector as a benchmark for the roofing sector.
} 
Table 3: Comparison of the roofing, the glazing, and the plumbing sector by various economic indicators

\begin{tabular}{l|rrr|r}
\hline \hline & Roofers & Plumbers & Glaziers & Source \\
\hline Number of companies & 11,295 & 37,720 & 3,752 & A, 1996 \\
Number of employees & 113,996 & 364,393 & 25,393 & A, 1996 \\
Avg. number of employees per company & 8.8 & 9.0 & 6.6 & A, 1996 \\
\hline Share of firms by revenues (in 1,000) & & & & B, 1996 \\
$<100 \mathrm{DM}$ & 6.8 & 8.8 & 13.6 & \\
$100-500 \mathrm{DM}$ & 24.6 & 33.7 & 42.6 & \\
$500-1,000 \mathrm{DM}$ & 26.1 & 23.5 & 21.5 & \\
$1,000-2,000 \mathrm{DM}$ & 25.1 & 19.3 & 13.5 & \\
$>2,000 \mathrm{DM}$ & 17.4 & 14.6 & 8.5 & \\
\hline Value added in $€$ per employee & 37,195 & 35,949 & 32,931 & $\mathrm{C}, 2001$ \\
Investments/employee (in $€$ ) & 1,472 & 1,229 & 2,482 & $\mathrm{C}, 2001$ \\
Share of labour costs (in \%) & 36.0 & 32.5 & 49.0 & $\mathrm{C}, 2001$ \\
Avg. gross daily wage/fulltime employee (in $€$ ) & 61.25 & 63.23 & 64.28 & $\mathrm{~A}, 1996$ \\
Number of companies/1 Mio. sector revenue & 1.3 & 1.3 & 0.6 & $\mathrm{~B}, 1996$ \\
\hline \hline
\end{tabular}

Note: A - BA data (see Section 3); B - Revenue tax statistics of the German Federal Statistical Office (Umsatzsteuerstatistik); C - Cost Structure Survey of the German Federal Statistical Office (Kostenstrukturerhebung)

roofing sector than the glazing sector. For the intersectoral comparison, the treatment group $g_{1}$, thus, corresponds to all workers of the roofing sector that are covered by the minimum wage regulations, while workers in the plumbing sector, who would have been covered if they worked in the roofing sector, are considered as the control group $g_{0}$. Hence, this approach can only be estimated based on the BA data. Treatment now refers to being covered by the minimum wage regulations and the resulting estimates give us the average employment effect for covered workers in the roofing sector if changes in employment outcomes of plumbers between the ex-ante situation $\left(t_{0}: 1994-1996\right)$ and the ex-post situation $\left(t_{1}: 1997-2007\right)$ capture the counterfactual change in employment outcomes for roofers in the absence of the minimum wage.

Moreover, we need to assume that there is no control group contamination, i.e. there is no indirect effect of the minimum wage regulations in the roofing sector on the plumbing sector. If the plumbing sector provides some substitutes for roofing services, for example, a negative employment effect in the roofing sector would boost employment in the plumbing sector, thereby overestimating a negative impact of the minimum wage. However, the lack of any evident improvement in the revenues realised by the plumbing sector relative to 
the roofing sector after the MW introduction puts doubt on such spillovers, see Figure 1 . Moreover, we find that transitions between both sectors are negligible and independent from the MW introduction. Both before and after 1997, only about $0.2 \%(0.1 \%)$ of all roofers (plumbers) enter the plumbing sector (roofing sector) in the next year.

Results. Descriptives regarding both the dependent variable and the set of covariates for both roofers and plumbers prior to and after the minimum wage introduction are provided in Appendix D. On average, 80\% (77\%) of all western (eastern) German roofers are still employed in the same sector after one year. The unconditional DiD of the dependent variable for the intersectoral comparison corresponds to 3 percentage points for western and -1 percentage point for eastern Germany. However, the DiD controlling for observable characteristics across sectors suggests some relevant changes in observables such as a relative increase in skilled workers in the roofing sector that needs to be controlled for in a regression approach. For the regression approach, $D_{i t}$ in equation (3) equals one for all roofers in the period after the minimum wage introduction $\left(t_{1}: 1997-2007\right)$.

Table 4 shows the marginal effect of $D_{i t}$ from equation (4) for the average worker in eastern and western Germany. As previously discussed, we compare estimates from a pooled logit and a pooled linear probability model and compare this to estimates from a linear probability model that takes account of individual-specific fixed effects. Irrespective of the specification, the minimum wage in eastern Germany appears to have reduced the chances for roofers to remain employed in the sector by around 2 to 3 percentage points on average compared to plumbers who have not been subject to minimum wage regulations. Adding firm-level covariates in column 2 compared to a specification that includes individual covariates only, does not have much influence on the estimated impact. Moreover, both the pooled Logit model and the pooled LPM yield quite similar results and, with only $0.4 \%$ of all observations falling outside the admissible range, the LPM estimator performs quite well. Controlling for time-constant unobservables at the individual level (column 4) yields very comparable results although the share of observations outside the $[0 ; 1]$ interval rises to still acceptable, albeit higher, $9.0 \%$. 
Table 4: Minimum wage effect on the probability of being employed in the roofing sector in the next year, intersectoral comparison based on BA data 1994-2007

\begin{tabular}{|c|c|c|c|c|}
\hline & $\begin{array}{c}(1) \\
\text { Pooled Logit }\end{array}$ & $\begin{array}{c}(2) \\
\text { Pooled Logit }\end{array}$ & $\begin{array}{c}(3) \\
\text { Pooled LPM }\end{array}$ & $\begin{array}{c}(4) \\
\text { FE LPM }\end{array}$ \\
\hline & \multicolumn{4}{|c|}{ Eastern Germany } \\
\hline ME of $D_{i t}$ in $\mathrm{pp}^{\mathrm{a}}$ & $-2.0^{* * *}$ & $-2.2^{* * *}$ & $-2.3^{* * *}$ & $-2.9^{* * *}$ \\
\hline Robust s.e. & $(0.3)$ & $(0.2)$ & $(0.3)$ & $(0.3)$ \\
\hline Obs. (in 1000) & 497 & 497 & 497 & 497 \\
\hline Share of $\hat{Y} \notin[0 ; 1]$ & $\mathrm{n} / \mathrm{a}$ & $\mathrm{n} / \mathrm{a}$ & $0.4 \%$ & $9.0 \%$ \\
\hline Individual covariates ${ }^{b}$ & Yes & Yes & Yes & Yes \\
\hline \multirow[t]{2}{*}{ Firm-level covariates ${ }^{\mathrm{c}}$} & No & Yes & Yes & Yes \\
\hline & \multicolumn{4}{|c|}{ Western Germany } \\
\hline ME of $D_{i t}$ in $\mathrm{pp}^{\mathrm{a}}$ & $2.0^{* * *}$ & $1.8^{* * *}$ & $1.2^{* * *}$ & $-1.2^{* * *}$ \\
\hline Robust s.e. & $(0.2)$ & $(0.2)$ & $(0.2)$ & $(0.2)$ \\
\hline Obs. (in 1000) & 1,110 & 1,110 & 1,110 & 1,110 \\
\hline Share of $\hat{Y} \notin[0 ; 1]$ & $\mathrm{n} / \mathrm{a}$ & $\mathrm{n} / \mathrm{a}$ & $0.9 \%$ & $0.4 \%$ \\
\hline Individual covariates $^{b}$ & Yes & Yes & Yes & Yes \\
\hline Firm-level covariates ${ }^{c}$ & No & Yes & Yes & Yes \\
\hline
\end{tabular}

a Marginal effect of $D_{i t}$ in percentage points; for logit estimations calculated as in equation (4)

b Occupational status and educational attainment (6 dummies) in the fixed effects estimations plus age, age $^{2}$, sex, 2 nd order polynomial of previous work experience in the sector and in the company in the pooled estimations

${ }^{c}$ Age and qualification of company workforce, company size (4 dummies), 2nd order polynomial of mean daily gross wage

Significance levels: $* 5 \%, * * 1 \%, * * * 0.1 \%$

In western Germany, the impact appears to be similarly robust when controlling for firm-level in addition to individual covariates. Both specifications indicate a positive minimum wage effect for roofers as compared to plumbers of around 2 percentage points. Also the pooled LPM model suggests a positive minimum wage effect, which is slightly lower than for the pooled logit models. However, when controlling for time-constant unobservable characteristics in the FE LPM specification, the findings for western Germany indicate that the chances for a roofer to remain employed in the next year after the minimum wage was introduced decrease by around 1 percentage point compared to plumbers who have not been subject to minimum wage regulations. This suggests that minimum wages in western Germany increased layoffs mainly among workers with poor unobservable characteristics so that pooled estimations are upward biased. 
Robustness. The validity of the previous results critically hinges on the common trends assumption. Unfortunately, we only have three years prior to the MW introduction in order to examine the pre-treatment trend in employment outcomes. For eastern Germany, Appendix D suggests a dip in employment chances in the roofing sector in 1996 that deviates from the trend in the plumbing sector. Indeed, placebo tests in Appendix E confirm the common trend assumption between 1994 and 1995, while there are significant deviations between 1995 and 1996. The decline in employment outcomes in 1996 may hint at anticipation effects since employment outcomes for the last pre-MW year are measured just three months prior to the MW introduction in October 1997. Excluding observations for 1996, however, suggests even somewhat stronger negative effects, see Table 5. If the dip in 1996 does not result from an anticipation effect, we should, however, not exclude this year but adjust our estimates for diverging trends. A corresponding extension of the previous estimation that allows for diverging trends across sectors mainly supports the previous findings with only the pooled LPM estimates deviating from the previous estimates. For western Germany, Appendix D suggests that there was a dip in employment outcomes for roofers relative to plumbers in 1995. Thus, compared to plumbers, the placebo tests suggest a less favourable trend for roofers between 1994 and 1995 but a positive trend from 1995 to 1996, see Appendix E. Estimations that allow for diverging trends across sectors, however, confirm the previous findings, see Table 5 .

Adjusting for diverging trends based on the few pre-MW years, however, may not suffice if the common trends assumption fails in the long run. As some tentative robustness check, we ran estimations that were extended by interacting the treatment indicator $D_{i t}$ to allow for a heterogeneous ATT for periods with distinct levels of a MW bite (19972001, 2002-2004 and 2005-2007) in order to examine the timing of the effect after the MW introduction. As shown in Table 5, the impact of the minimum wage in eastern Germany was significantly negative in all three sub-periods. Moreover, according to the preferred fixed-effects specification, the strongest impact occurred in the second period after the minimum wage was raised to the level in western Germany. In western Germany, the fixed effects specification also suggests that the minimum wage impact was strongest in 
Table 5: Marginal effect of $D_{i t}$ in percentage points for various robustness checks of the intersectoral comparison in Table 4

\begin{tabular}{l|cccc}
\hline \hline & $\begin{array}{c}(1) \\
\text { Pooled } \\
\text { Logit }\end{array}$ & $\begin{array}{c}(2) \\
\text { Pooled } \\
\text { LPM }\end{array}$ & $\begin{array}{c}(3) \\
\text { LE }\end{array}$ & $\begin{array}{c}\text { Obs. } \\
\text { (in 1000) }\end{array}$ \\
\hline \multicolumn{4}{c}{ Eastern Germany } \\
Sample without 1996 & $-3.4^{* * *}$ & $-3.6^{* * *}$ & $-3.4^{* * *}$ & 400 \\
Trend-adjusted DiD & $-2.1^{* * *}$ & 0.7 & $-1.8^{* * *}$ & 497 \\
Extension with period-wise effects & & & & \\
ME of $D_{i t} x t_{97-01}$ in pp & $-1.3^{* * *}$ & $-1.7^{* * *}$ & $-3.1^{* * *}$ & \\
ME of $D_{i t} x t_{02-04}$ in pp & $-3.0^{* * *}$ & $-2.8^{* * *}$ & $-3.6^{* * *}$ & 497 \\
ME of $D_{i t} x t_{05-07}$ in pp & $-4.7^{* * *}$ & $-3.7^{* * *}$ & $-2.7^{* * *}$ & \\
\hline \multicolumn{4}{c}{ Western Germany } \\
Trend-adjusted DiD & $2.6^{* * *}$ & $1.6^{* * *}$ & $-1.2^{* * *}$ & 1,110 \\
Extension with period-wise effects & & & & \\
ME of $D_{i t} x t_{97-01}$ in pp & $1.8^{* * *}$ & $1.0^{* * *}$ & $-1.3^{* * *}$ & \\
ME of $D_{i t} x t_{02-04}$ in pp & $1.5^{* * *}$ & $0.7^{* * *}$ & $-1.8^{* * *}$ & 1,110 \\
ME of $D_{i t} x t_{05-07}$ in pp & $1.8^{* * *}$ & $1.9^{* * *}$ & $-0.6^{* *}$ & \\
\hline \hline
\end{tabular}

Note: Same specification as in Table 4 with individual and firm-level controls;

Significance levels: * $5 \%,{ }^{* *} 1 \%, * * * 0.1 \%$

the intermediate period, followed by the period after its introduction. The smaller effect in the last period may suggest that firms were able to bear the additional costs that were imposed by the minimum wage during these years of economic revival in the western German roofing sector. All in all, the estimation results appear to be quite robust and also show a plausible impact pattern across time.

\subsection{Comparison within the roofing sector}

Approach. The treatment group $g_{1}$ in this approach corresponds to roofers with a binding MW due to earning a wage in June that is below the minimum wage level that takes effect until June of the next year. For the pre-regulation years, we consider someone to belong to the treatment group if his wage falls below the minimum wage level that would have to be applied in the pre-regulation years given the increases of the median nominal wage in the LAK data. Workers of the roofing sector whose wages are above that minimum level are used as the control group $g_{0}$. While we are able to exactly identify these groups in the LAK data, we define $g_{1}$ in the BA data to encompass all covered 
workers whose probability to fall below the minimum wage level exceeds $50 \% .15$

Hence, the treatment indicator $D_{i t}$ equals one for all covered workers with a binding minimum wage after the MW introduction and zero otherwise. The resulting estimates give the average treatment effect on the treated if changes in employment outcomes for workers without a binding MW between the ex-ante situation $\left(t_{0}: 1995-1996\right)^{16}$ and the expost situation $\left(t_{1}: 1997-2007\right)$ capture the counterfactual change in employment outcomes for the treated roofers in the absence of the minimum wage. To the extent that all roofers are affected by the same demand conditions, this is clearly a plausible assumption. However, for a period of 13 years that we cover in the estimations, diverging trends may arise due to skill-biased technological advances. We will return to this potential problem in the robustness section. Moreover, the suggested approach only yields unbiased estimates if there are no minimum wage induced employment effects for workers without a binding minimum wage. In fact, note that, if all identifying assumptions hold, the intersectoral comparison and the estimate of the comparison within the roofing sector yield the same employment effects for an average covered worker in the roofing sector.

Results. This approach can be estimated using both the BA and LAK data. Corresponding descriptives for the BA data are provided in Appendix F 17 The unconditional DiD for the probability of still being employed in the next year indicates strong positive effects, but this raw DiD has to be interpreted with caution. Since the minimum wage level repeatedly increased after 1998, the share of individuals with a binding MW also increased until 2008 (see Table 4). As a consequence, the pool of workers with a binding MW is likely to improve across time resulting in upward biased estimates. We therefore decided to exploit the variation in the status of being affected by a binding MW across time on the individual level by taking account of individual fixed effects. In fact, the pooled Logit and pooled LPM model show strongly positive and comparable employment effects that are likely to reflect the described non-comparability of the pool of workers

\footnotetext{
${ }^{15} \mathrm{~A}$ specification with $P_{M W}$ as a continuous treatment variable gave similar results.

${ }^{16}$ Note that we have only two pre-regulation years because the LAK data that are used for imputing hourly wages are only available from 1995 onwards.

${ }^{17}$ Descriptives for the LAK data are available from the authors upon request.
} 
with a binding MW prior to and after the MW introduction. Since we do not consider these estimates informative, Table 6 reports the estimates for the fixed effects LPM only ${ }^{18}$

The DiD results for eastern Germany in columns (1) and (2) indicate that workers with a binding MW were 9 to 10 percentage points less likely to remain employed after the MW introduction relative to workers without a binding MW. This negative effect is confirmed by both the LAK and BA data suggesting that the BA data yield quite reliable estimates despite the imprecision in the distinction between workers with and without a binding MW. For western Germany, the LAK data show an insignificant reduction in the probability of continued employment by -2.7 percentage points, while the treatment effect is slightly larger and significant at the $5 \%$ significance level when using the BA data 19

If all identifying assumptions regarding common trends in the absence of the treatment and the lack of any spillovers held, multiplying the ATT from the comparison of workers with and without a binding MW within the roofing sector in Table6 by the share of workers with a binding MW should yield the ATT from the previous intersectoral comparison, i.e. the average effect for all covered workers in the roofing sector ${ }^{20}$ The implied ATT for covered workers are included in Table 6. For eastern Germany, this yields an ATT for all covered workers of $-2.0(=-10.0 \times 0.204)$ percentage points for the BA results since, on average, $20.4 \%$ of all workers in eastern Germany are affected by a binding MW across the entire period. In western Germany, the MW is binding for $5.5 \%$ of the workforce on average, implying an ATT for all covered workers of $-0.3 \%$ percentage points. Compared to the fixed-effects estimates in Table 4 , the fixed-effects estimates in Table 6 appear to be underestimated. Since we consider the assumptions underlying the previous intersectoral comparison plausible given the robustness checks, this deviation either indicates that the

\footnotetext{
${ }^{18}$ As an alternative, one could evaluate each minimum wage level separately by defining workers with and without a binding MW corresponding to each MW level. However, corresponding estimates did not show any clear pattern, thus indicating that anticipation effects or the catching up with past increases make it difficult to isolate the impact of subsequent MW increases.

${ }^{19}$ When including individuals with a minor employment in the LAK estimates, the treatment effect amounts to highly significant -17.3 percentage points. For a better comparability with the BA data, we leave these individuals out. Still, the estimates with minor employment indicate that the MW may have had a strong effect on their employment chances, a finding that should be approached in future research.

${ }^{20}$ This is the case because the comparison within the roofing sector assumes a zero effect of the MW for workers without a binding MW.
} 
Table 6: Minimum wage effect on the probability of being employed in the roofing sector in the next year, DiD estimations between workers with and without a binding MW, BA and LAK data 1995-2007

\begin{tabular}{|c|c|c|c|c|}
\hline & $\begin{array}{c}(1) \\
\text { DiD }^{a} \\
\text { LAK }\end{array}$ & $\begin{array}{l}(2) \\
\text { DiD } \\
\text { BA }\end{array}$ & $\begin{array}{c}(3) \\
\operatorname{taDiD}^{\mathrm{b}} \\
\mathrm{BA}\end{array}$ & $\begin{array}{c}(4) \\
\text { DiDiD }^{\mathrm{c}} \\
\text { BA }\end{array}$ \\
\hline \multicolumn{5}{|l|}{ Eastern Germany } \\
\hline $\mathrm{ME}$ of $D_{i t}$ in $\mathrm{pp}^{\mathrm{d}}$ & $-8.5^{* * *}$ & $-10.0^{* * *}$ & $-8.8^{* * *}$ & $-5.6^{* * *}$ \\
\hline Robust s.e. & $(0.7)$ & $(0.8)$ & $(1.1)$ & $(1.2)$ \\
\hline Obs. (in 1000) & 288 & 224 & 224 & 446 \\
\hline Share of $\hat{Y} \notin[0 ; 1]$ & $7.3 \%$ & $8.6 \%$ & $4.0 \%$ & $6.9 \%$ \\
\hline ATT for all covered workers & -1.7 & -2.0 & -1.8 & -1.1 \\
\hline \multicolumn{5}{|l|}{ Western Germany } \\
\hline $\mathrm{ME}$ of $D_{i t}$ in $\mathrm{pp}^{\mathrm{d}}$ & -2.7 & $-5.0^{*}$ & -0.8 & $-7.2^{*}$ \\
\hline Robust s.e. & $(2.3)$ & $(2.0)$ & $(2.5)$ & $(2.9)$ \\
\hline Obs. (in 1000) & 601 & 457 & 457 & 1,013 \\
\hline Share of $\hat{Y} \notin[0 ; 1]$ & $0.1 \%$ & $0.9 \%$ & $0.1 \%$ & $3.6 \%$ \\
\hline ATT for all covered workers & -0.1 & -0.3 & -0.04 & -0.4 \\
\hline
\end{tabular}

${ }^{a}$ DiD estimation for workers with and without a binding MW within the roofing sector

b Trend-adjusted DiD estimation for workers with and without a binding MW within the roofing sector

${ }^{c}$ DiDiD estimation for workers with and without a binding MW within the roofing sector compared to the plumbing sector

${ }^{\mathrm{d}}$ Marginal effect in percentage points for the treatment indicator $D_{i t}$ from a linear probability model with individual fixed effects; all estimations include individual and firm level covariates as in Table 4 for the BA data and the same covariates except educational attainment for the LAK data. Significance levels: * $5 \%, * * 1 \%, * * * 0.1 \%$

common trend assumption between workers with and without a binding MW is violated and/or that workers without a binding MW must be indirectly and negatively affected by the MW.

Robustness. In order to rule out that the observed deviation between the ATT from both estimation approaches results from a violation of the common trends assumption between workers with and without a binding MW, we need to test the robustness of this assumption. Therefore, we examine placebo tests for the two years that are available prior to the MW introduction, see Appendix E. While the placebo test confirms the common trend for western Germany, the placebo test for eastern Germany is insignificant only for the LAK data but suggests a diverging trend based on the BA data despite the fact that estimation results were quite comparable across data sets. Surprisingly, however, 
allowing for diverging trends between workers with and without a binding MW does not alter the estimation results much for eastern Germany, but suggests an insignificant negative impact for western Germany, see column (3) in Table 6 .

Since the observable pre-regulation period is, however, very short, it is questionable to what extent placebo tests may confirm or disprove the validity of the common trends assumption for the whole period and to what extent trend-adjusted estimations based on this short pre-regulation period help to tackle a potential violation of this assumption. Moreover, diverging trends in the long run due to, for example, skill-biased technological advances might still bias our estimates.

As an alternative robustness check, we therefore capture the potentially diverging trends in the absence of the MW between workers with and without a binding MW by using comparable workers from the plumbing sector as an additional benchmark. In particular, we identify those plumbers for whom the minimum wage would have been binding if they worked in the roofing sector given their individual and firm characteristics. We do so by imputing the wage plumbers would receive in the roofing sector given their characteristics, thus applying the wage imputation described in Section 3 not only to roofers but also to plumbers and estimating the probability of being bound by the minimum wage $\left(P_{M W}\right)$ analogous to roofers. Appendix $\mathrm{G}$ indicates that the distribution of $P_{M W}$ is astonishingly similar across sectors, thus indicating the similarity of both sectors with respect to observable characteristics. Hence, if we think about the imputation of the counterfactual $P_{M W}$ among plumbers as an approach that is similar to matching individuals with a similar treatment intensity, the necessary common support along the whole distribution seems to be given.

We then use plumbers with and without a counterfactually binding MW to run a DiDiD estimation where the treatment indicator $D_{i t}$ equals one for workers of the roofing sector with a binding MW after the MW introduction and zero for all other groups and time periods. If roofers with and without a binding MW had experienced different trends in their employment chances even in the absence of the minimum wage, reflecting, for example, skill-biased technological progress, we assume that plumbers with and without 
a counterfactually binding MW capture these diverging trends across time. The corresponding DiDiD results in column (4) of Table 6 indicate that the employment effect in eastern Germany continues to be negative, but somewhat smaller. This may suggest that part of the negative effect in Table 6 is in fact due to a negative trend for workers with a binding MW relative to workers without a binding MW. Since representatives of the roofing sector repeatedly mentioned the need for catching up with technological progress in eastern Germany (see Aretz et al. 2011), this appears a plausible finding. For western Germany, the difference between the DiD and DiDiD estimates are smaller and suggest that trends in western Germany rather diverge in the opposite direction. More importantly, we find that the implied ATT for an average covered worker is smaller than suggested by the intersectoral comparison in the previous section. Therefore, employment spillovers between workers with and without a binding MW remain the prime suspect for this deviation, a hypothesis that we examine in the next section.

\section{$7 \quad$ Making employment spillovers visible}

Approach. The treatment group $g_{1}$ corresponds to all workers of the roofing sector who are covered by the minimum wage regulations, while workers in the plumbing sector, who would have been covered if they worked in the roofing sector, are considered as the control group $g_{0}$. However, we do not estimate the average employment effect for covered roofers as in the intersectoral comparison in Section 6, but allow the treatment effect to differ by binding status. In particular, we distinguish between workers with a binding MW $\left(p_{1}=P_{M W}>0.5\right)$, workers with wages significantly above the minimum level $\left(p_{3}=P_{M W}<0.1\right)$ and an intermediate group of workers $p_{2}$ for whom $P_{M W}$ ranges between these extremes. Since we have estimated the counterfactual probability of earning a wage below the MW for workers in the plumbing sector, we are thus able to extend the DiD framework to identify the treatment effect for all three groups:

$$
P\left(e_{i t+1}=1\right)=\kappa_{p}+\alpha_{g \times p}+\gamma_{t \times p}+\delta D_{i t} \times p+\beta X_{i t}+c_{i}+\epsilon_{i t}
$$


where $\kappa_{p}$ captures the time constant difference between workers of a different binding status and $\alpha_{g \times p}$ captures the time constant deviation between roofers and plumbers of the same binding status. Furthermore, $\gamma_{t \times p}$ allows for changes in employment outcomes of workers with a particular binding status across time that are common to roofers and plumbers, while the same set of covariates $X$ as before controls for observable differences across workers. The treatment indicator $D_{i t}$ equals one for covered roofers in the period after the MW introduction (1997-2007) and zero for plumbers as well as roofers in the ex-ante period (1995-1996). This treatment indicator is interacted with the binding status so that we get an ATT for all three groups of workers. If spillover effects are relevant, we should observe non-zero outcomes for workers with wages above the minimum level, i.e. with $P_{M W}<0.5$.

Note that due to the change in the pool of workers with a particular binding status across time (see previous section), we again use a fixed-effects linear probability model for estimation, i.e we exploit the change in binding status across time on the individual level for identification by including $c_{i}$ in equation (5). The identifying assumption is that plumbers and roofers with the same set of covariates $X$ and the same changes in the binding status would experience comparable changes in employment outcomes across time in the absence of the MW. In fact, note that this assumption is less strict than the assumption in Section 6.1 because we condition on the binding status in addition to $X$.

Results. Columns (1) and (3) in Table 7 show the estimated impact of the minimum wage on the probability of still being employed in the sector in the next year by binding status of the worker. The outcomes for workers with a binding $\mathrm{MW}\left(p_{1}\right)$ range around -9 percentage points in both eastern and western Germany. As expected from the previous discussion, the estimated treatment effect for workers with wages above the minimum wage level significantly differs from zero and suggests employment spillovers. For the intermediate group $\left(p_{2}\right)$, the chances of remaining employed in the roofing sector are reduced by almost 5 percentage points in eastern Germany and by almost 4 percentage points in western Germany. Even for workers whose probability to fall below the MW is 
Table 7: Minimum wage effect on the probability of being employed in the roofing sector in the next year, intersectoral DiD estimations by binding status, BA data 1995-2007

\begin{tabular}{l|cc|cc}
\hline \hline & \multicolumn{2}{|c}{ Eastern } & Germany & \multicolumn{2}{c}{ Western Germany } \\
& $(1)$ & $(2)$ & $(3)$ & $(4)$ \\
FE LPM with trend adjustment? & $\mathrm{No}^{\mathrm{b}}$ & Yes $^{\mathrm{c}}$ & $\mathrm{No}^{\mathrm{b}}$ & Yes $^{\mathrm{c}}$ \\
\hline ME of $D_{i t} \times p_{1}$ in $\mathrm{pp}^{\mathrm{a}}$ & $-8.6^{* * *}$ & $-8.5^{* * *}$ & $-8.8^{* * *}$ & $-8.4^{* * *}$ \\
ME of $D_{i t} \times p_{2}$ in $\mathrm{pp}^{\mathrm{a}}$ & $-4.8^{* * *}$ & $-4.7^{* * *}$ & $-3.7^{*}$ & $-3.7^{*}$ \\
ME of $D_{i t} \times p_{3}$ in $\mathrm{pp}^{\mathrm{a}}$ & $-2.8^{* * *}$ & $-2.4^{* * *}$ & $-1.2^{* * *}$ & $-1.5^{* *}$ \\
Obs. in 1,000 & 446 & 446 & 1,013 & 1,013 \\
Implied ATT analogue to section 6.1 & -4.4 & -4.1 & -1.8 & -2.0 \\
\hline \hline
\end{tabular}

${ }^{\text {a }}$ Marginal effect of the treatment in percentage points by binding status $p$.

${ }^{\mathrm{b}}$ Linear DiD estimation as in equation (5); covariates $X$ as in Table 6 .

${ }^{c}$ Linear DiD estimation as in equation (5) extended by sector-specific time trends; covariates $X$ as in Table 6

Significance levels: $* 5 \%, * * 1 \%, * * * 0.1 \%$

less than $10 \%$, we find an increased risk of leaving the roofing sector of almost 3 percentage points in eastern Germany and around 1 percentage point in western Germany. Note that these findings imply an ATT for an average covered roofer that is largely in line with the estimates in Section 6.1 ${ }^{21}$ However, the effect is not only caused by workers with a binding MW, but to a lesser extent also by workers who are not affected by a binding MW. Therefore, the ATT for workers with a binding MW relative to workers without a binding MW in Section 6 is downward biased.

Robustness. Note that interpreting the above cross-sector comparisons for workers of a different binding status as evidence for employment effects for workers who earn a wage above the minimum wage threshold rests on several assumptions. First of all, spillovers between the sectors need to be at least negligible compared to spillovers between workers within the roofing sector. As discussed in Section 6.1, we consider this to be a plausible assumption given the low and quite time-constant rate of intersectoral transitions of workers. Secondly, roofers and plumbers of a particular binding status must have experienced a similar trend in employment outcomes in the absence of the MW. We test for the robustness of the common trends assumption by allowing for different trends across sectors based on the years prior to the MW introduction. The results in Table 7 suggest

\footnotetext{
${ }^{21}$ This implied ATT results from calculating the weighted ATT across the three groups of workers that differ by binding status.
} 
that the trend-adjustment does not have much of an effect on the estimation results.

However, the common trends assumption could fail in the long run, and a trendadjustment based on two pre-regulation years may not suffice to tackle the problem. Also, a concern with the previous estimates might be that there is some statistical uncertainty regarding the binding status of the worker due to the imputation. In other words, even the group that is considered to be unaffected by a binding MW $\left(p_{3}\right)$ still has a probability of earning a wage below the minimum wage level of up to $10 \%$. As a result, the previous results might simply reflect the individuals within each group for whom the MW is in fact binding.

In order to counteract such concerns, we conduct the previous intersectoral comparison along the deciles of the wage distribution and distinguish between three sub-periods that differ by bite (1997-2001; 2002-2004; 2005-2007). As an advantage, we also observe wage deciles for which the probability of being affected by a binding MW is zero or very close to zero, see Appendix $\mathrm{H}$ for corresponding descriptives. Effects on these deciles cannot be driven by the previously mentioned measurement problem. Secondly, we are able to examine whether the pattern of employment effects follows the extension of the bite to higher wage deciles across time. Using again the counterfactual wage for plumbers if they worked in the roofing sector, we thus estimate the ATTs for each wage decile by exchanging $p$ in equation (5) by the decile $d_{i t}=1, \ldots, 10$ and by further interacting $D_{i t} \times d_{i t}$ with the three sub-periods. Note in Appendix $\mathrm{H}$ that the share of plumbers whose counterfactual wage falls in the lowest wage decile is quite high due to the wage compression in the roofing sector. Still, we have high numbers of observations in the plumbing sector for each wage decile in the roofing sector so that we are able to estimate the ATT for each decile. The approach is related to the study of Neumark et al. (2004), who also study the minimum wage effects throughout the wage distribution. Compared to our study, the authors exploit the regional and time variation of the minimum wage level in the UK and look at next years' employment status along the wage distribution, defined as the distribution of initial earnings relative to the old minimum wage.

Figure 4 displays the corresponding marginal effects on the probability of continued 
Figure 4: Minimum wage effect on the probability of being employed in the roofing sector in the next year by decile of the wage distribution and sub-period, by Western (top) and Eastern Germany (bottom), BA data 1995-2007

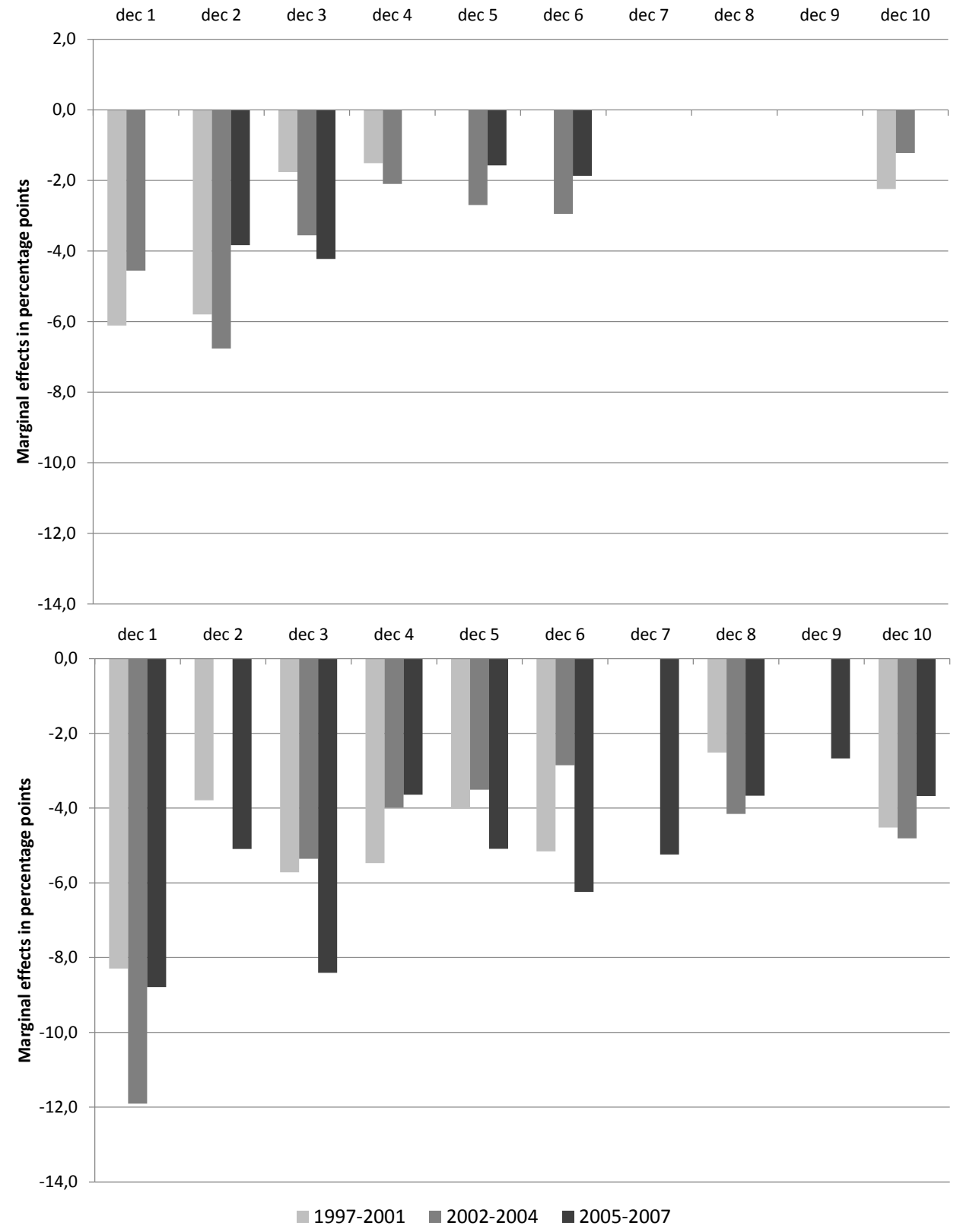

Note: The figures only display effects that are significant at least at the $5 \%$ significance level.

employment in the roofing sector in percentage points as long as the effect is significant at least at the $5 \%$ level. The results indicate that the prospects of continued employment in eastern Germany have deteriorated due to the minimum wage almost along the entire wage distribution in eastern Germany. Moreover, note that the impact on workers with wages in the upper wage deciles are partially significant only for the latest period where the bite of the minimum wage was strongest. For western Germany, wage deciles that 
are not affected by a binding MW appear to be less affected by the MW. For workers whose wages fall in the 7th to 9th decile, no significant effects can be found at all. Still, there is some evidence for employment spillovers in line with the previous results because workers in the 3rd to 6th decile, for whom we find a decline in the chances of continued employment, are only marginally affected by a binding MW (see Appendix H). Also, the effect seems to follow the extended bite of the MW since wage deciles 5 and 6 are only affected in the later periods with a higher minimum wage level. The negative effect on continued employment of roofers in the 10th decile might be caused by voluntary quits of predominantly master craftsmen who leave the sample by deciding to become self-employed and to establish a single-person company whose share of all companies markedly increased during the observation period.

This additional analysis confirms that there are relevant spillovers in eastern Germany whose temporal pattern confirms a link to the extending minimum wage bite. For western Germany, employment spillovers are less strong but seem to exist for workers earning wages just above the minimum wage and for workers in the highest wage decile. These negative employment outcomes for workers with wages above the MW allow for two not necessarily competing explanations. On the one hand, the observed result pattern may suggest that workers are substituted by capital and that the substitutability differs for different types of workers with the least skilled workers being easiest to substitute. On the other hand, the result pattern is compatible with negative scale effects that mostly, if not for all workers, dominate a positive substitution effect between different types of workers. Of course, both explanations may be relevant to some extent, albeit qualitative interviews with leading experts in the roofing sector (see Aretz et al. 2011) suggest that the first may be the dominant explanation. In particular, the insiders doubt that the minimum wage in the roofing sector had much of a scale effect while the relevance of technological advances such as the introduction of new roofing systems that reduce the necessary labour input have been stressed.

The results are partly in line with Neumark et al. (2004), who find that workers whose wages are initially close to the minimum wage (up to 1.3 times the minimum wage) are 
most likely to be affected by changes in the wage floor. However, the authors find no evidence for spillovers in the upper part of the wage distribution, as opposed to our study.

\section{Conclusion}

This paper analysed the impact of minimum wages in the German roofing sector on workers' chances of continued employment. For the identification of average employment outcomes, we contrasted the estimated minimum wage impact when comparing the chances of continued employment in the roofing sector with a control sector and when comparing the chances of roofers with and without a binding minimum wage. In addition, we estimate the causal impact of the minimum wage for workers with and without a binding minimum wage as well as along the entire wage distribution. We are, thus, able to also identify indirect effects of the minimum wage on workers in the upper parts of the wage distribution for whom the MW is not binding. Our main conclusions are:

- On average, the minimum wage in the roofing sector resulted in poorer chances of remaining employed according to both the intersectoral comparison as well as the comparison of workers with and without a binding minimum wage within the roofing sector. This is especially true for eastern Germany, whose minimum wage level gave rise to a much higher share of affected workers of about $57 \%$ compared to $12 \%$ in western Germany. Given the limited compliance with the minimum wage regulations, the impact could even be stronger if compliance was fully enforced.

- Estimates from the comparison of workers with and without a binding minimum wage seem to be underestimated compared to estimates from an intersectoral comparison. If one is willing to assume that the common trend assumption holds and that the control sector is not affected by spillover effects, assumptions that are supported by some robustness checks, this deviation indicates that the minimum wage also affects the employment chances of roofers who are not directly affected by a binding minimum wage. 
- Running an intersectoral comparison of employment chances along the entire wage distribution by exploiting the counterfactual position of workers of the control sector in the wage distribution of the roofing sector confirms this previous suspicion. The prospects of continued employment deteriorated due to the minimum wage along the entire wage distribution in eastern Germany. In western Germany, spillovers are less strong but also exist for workers just above the minimum wage level.

- The decline in employment chances among workers without a binding minimum wage may indicate that scale effects dominate substitution effects and/or that minimum wages induce some capital-labour substitution. While both may be relevant to some extent, the latter may be the dominant force according to interviews that we conducted with sector insiders. In particular, they consider new roofing systems as a potential means of reducing minimum-wage induced labour costs but question a strong decline in output since the demand for roofing services appears to be rather price-inelastic.

These findings on the impact of the minimum wage regulations on the chances of continued employment should not, however, be equated with the overall minimum wage impact on the sector's employment. In particular, the single-person companies, whose share among all companies tripled during the observation period to $23 \%$ in 2010 , are not accounted for by our analysis. Furthermore, given the specific conditions of the roofing sector, e.g. the rather high level of qualification and the low labour intensity, a transferability of the results to other sectors which might be subject to minimum wage regulations in the future has to be viewed with caution.

Despite these reservations, the presented evidence clearly highlights the need for a broader perspective on employment effects of minimum wages by also taking a closer look at workers who do not appear to be affected by the minimum wage at a first glance. Moreover, our results put doubt on any attempts to identify employment effects of minimum wages by comparing workers with and without a binding minimum wage within a covered sector. 


\section{References}

Abowd, J., And M. Killingsworth (1981): "Structural models of the effects of minimum wages on employment by age groups," Report of the minimum wage study commission, 5, 143-169.

Abowd, J. M., F. Kramarz, D. N. Margolis, and T. Philippon (2000): "The Tail of Two Countries: Minimum Wages and Employment in France and the United States," IZA Discussion Papers 203.

Aretz, B., M. Arntz, S. Gottschalk, T. Gregory, M. Niefert, C. RamMER, H. SchröDER, And H. Schütz (2011): "ZEW-Studie zu den Wirkungen eines Mindestlohns in der Dachdeckerwirtschaft," Research report for the federal ministry of labour and social affairs.

Brown, C. (1999): "Minimum wages, employment, and the distribution of income," Handbook of Labor Economics, 3, 2101-2163.

Card, D., And A. Krueger (2000): "Minimum wages and employment: a case study of the fast-food industry in New Jersey and Pennsylvania: reply," The American Economic Review, 90(5), 1397-1420.

Currie, J., And B. Fallick (1996): "The Minimum Wage and the Employment of Youth Evidence from the NLSY," Journal of Human Resources, pp. 404-428.

Dolton, P., And C. Bondibene (2011): "An Evaluation of the International Experience of Minimum Wages in an Economic Downturn," Research report for the low pay commission, Royal Holloway, University of London.

Drews, N. (2008): "Das Regionalfile der IAB-Beschäftigtenstichprobe," FDZ Datenreport 2, Institute for Employment Research (IAB), Nuremberg.

Dube, A., T. Lester, and M. Reich (2010): "Minimum wage effects across state borders: Estimates using contiguous counties," The Review of Economics and Statistics, 92(4), 945-964. 
Dube, A., S. Naidu, And M. Reich (2007): "The Economic Effects of a Citywide Minimum Wage," Industrial and Labor Relations Review, 60(4), 522-543.

Fairris, D., And L. Bujanda (2008): "The Dissipation of Minimum Wage Gains for Workers through Labor-Labor Substitution: Evidence from the Los Angeles Living Wage Ordinance," Southern Economic Journal, 75(2), 473-496.

Hethey-Maier, T., And S. Seth (2010): “The Establishment History Panel (BHP) 1975-2008: Handbook Version 1.0. 2," FDZ Datenreport 4, Institute for Employment Research (IAB), Nuremberg.

Hsing, Y. (2000): "On the substitution effect of the minimum wage increase: new evidence," Applied Economics Letters, 7(4), 225-228.

Linneman, P. (1982): "The Economic Impacts of Minimum Wage Laws: A New Look at an Old Question," Journal of Political Economy, 90(3), 443-69.

Machin, S., A. Manning, and L. Rahman (2003): "Where the minimum wage bites hard: introduction of minimum wages to a low wage sector," Journal of the European Economic Association, 1(1), 154-180.

Neumark, D., D. Schweitzer, and D. Wascher (2004): "Minimum Wage Effects throughout the Wage Distribution," Journal of Human Resources, 39(2).

Neumark, D., And W. Wascher (1994): "Employment effects of minimum and subminimum wages: Reply to Card, Katz, and Krueger," Industrial and Labor Relations Review, 47(3), 497-512.

(1995): "Minimum-wage effects on school and work transitions of teenagers," The American Economic Review, 85(2), 244-249.

- (2000): "Minimum wages and employment: A case study of the fast-food industry in New Jersey and Pennsylvania: Comment," The American Economic Review, 90(5), 1362-1396. 
Neumark, D., And W. Wascher (2008): Minimum wages. The MIT Press.

Puhani, P. (2008): "The Treatment Effect, the Cross Difference, and the Interaction Term in Nonlinear Difference-in-Differences Models," IZA Discussion Papers 3478.

Wooldridge, J. (2002): Econometric Analysis of Cross Section and Panel Data. MIT Press. 


\section{Appendix}

A - Evolution of the employment across sectors by region, year $1997=100,1994-2008, \mathrm{BA}$ data

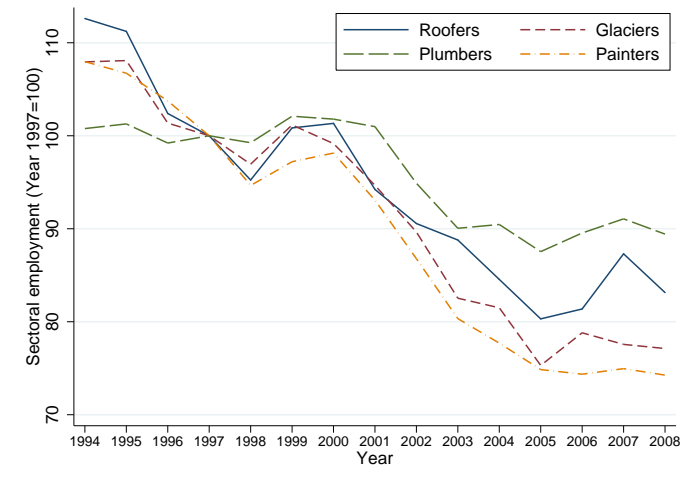

(a) Western Germany

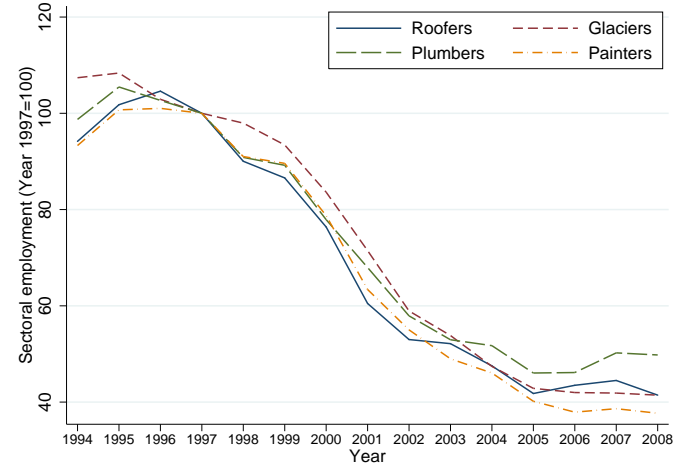

(b) Eastern Germany

B - Distributions of observed LAK and predicted BA data wage
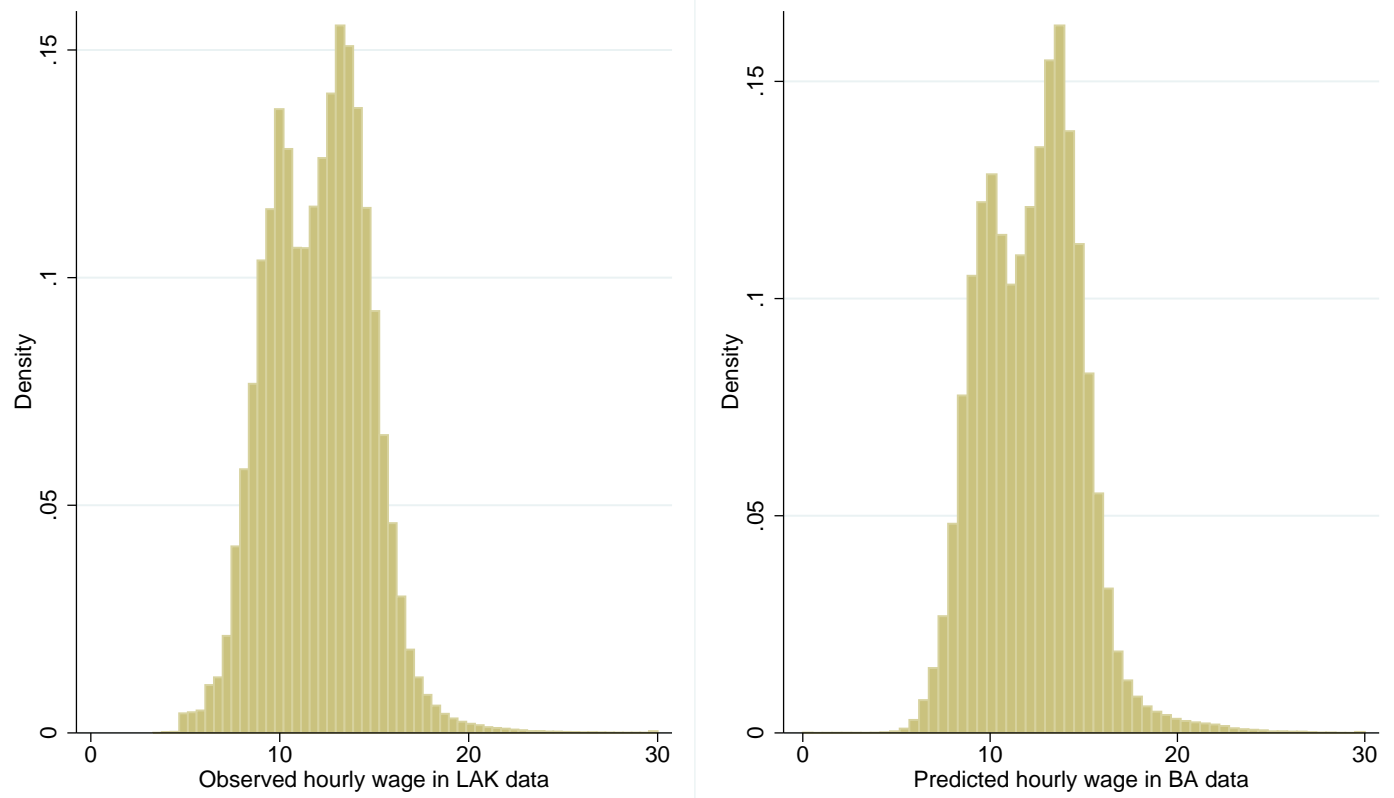


\section{C - Explanation of the underestimation of the bite in the BA data}

The compressed wage distribution which is observed in Figure 3 indicates that the imputation technique, which we use for implementing a hourly wage in the BA data and which assumes a normal distribution of wages, leads to a systematic underestimation of the share of workers with a binding MW in eastern Germany. For illustration, consider two types of workers that capture the asymmetric form of the wage distribution. Type A's wage roughly corresponds to the MW, whereas type B's wage lies somewhere above the MW level. Due to the fact that there is uncertainty which individual falls into which category, the imputed distribution of the predicted mean wage always reflects a mixing distribution of these two types. As a consequence, the imputed variance for type $\mathrm{A}$ is an overestimation whereas type B's imputed wage variance is an underestimation of the true variance. As a result, too much probability mass for type A is above the MW and too little probability mass for type B is below the MW, resulting in an underestimation of the share of workers with a binding MW. Still, the probability of being affected by a binding MW on an individual level should be highly related to the treatment intensity, i.e. the higher this probability on an individual level is, the more likely is an individual to fall below the MW threshold and the higher is the need for increasing the wage in order to comply with the MW level. 


\section{D - Mean values of independent and dependent variables by sec- tor prior to and after the MW introduction}

D.1 - Eastern Germany, BA data, 1994 - 2007

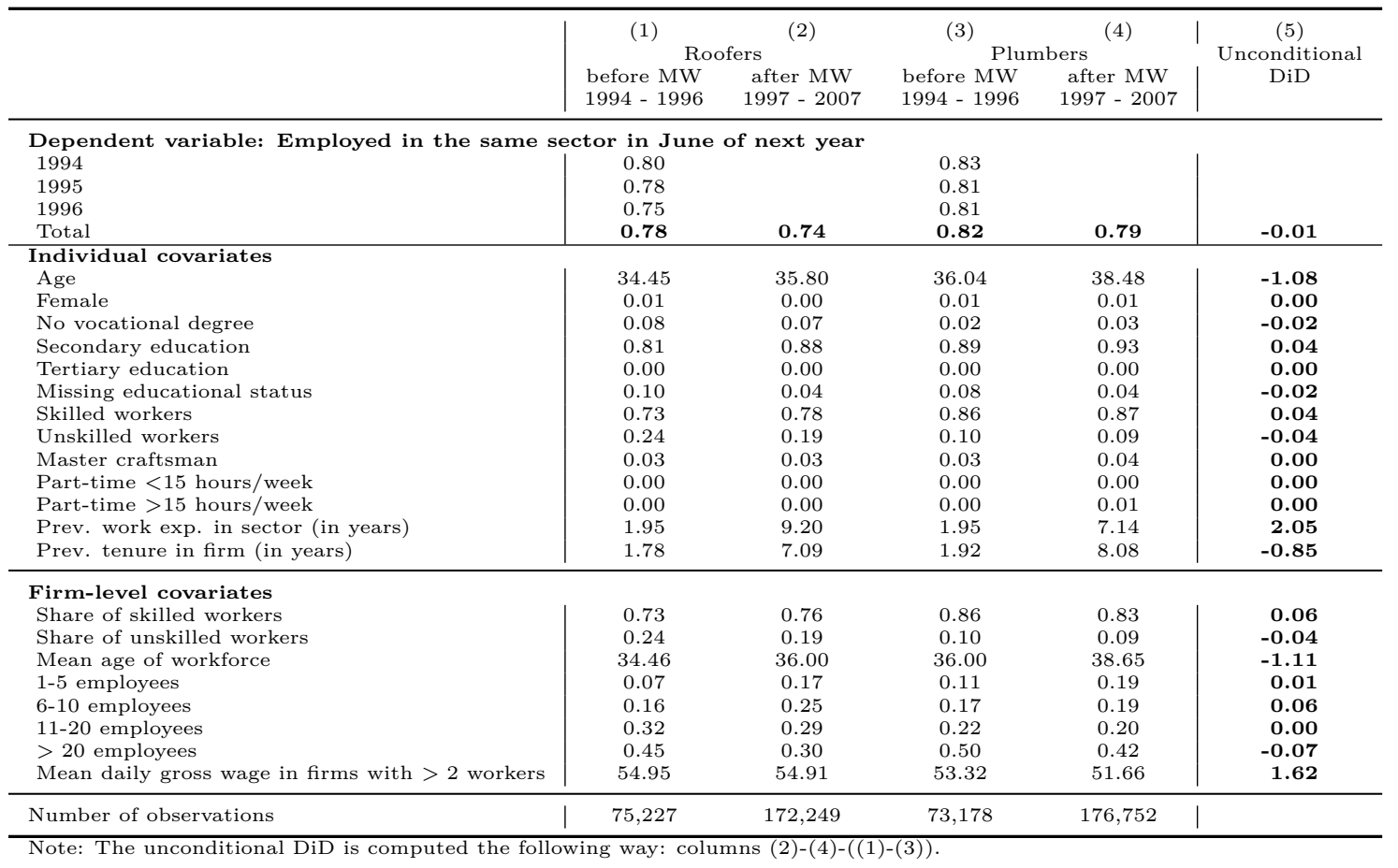

D.2 - Western Germany, BA data, 1994 - 2007

\begin{tabular}{|c|c|c|c|c|c|}
\hline & \multicolumn{2}{|c|}{ (1) (2) } & \multicolumn{2}{|c|}{ (3) (4) } & \multirow{3}{*}{$\begin{array}{c}(5) \\
\text { Unconditional } \\
\text { DiD }\end{array}$} \\
\hline & before MW & after MW & before MW & after MW & \\
\hline & $1994-1996$ & $1997-2007$ & $1994-1996$ & $1997-2007$ & \\
\hline \multicolumn{6}{|c|}{ Dependent variable: Employed in the same sector in June of next year } \\
\hline 1994 & 0.81 & & 0.87 & & \\
\hline 1995 & 0.79 & & 0.87 & & \\
\hline 1996 & 0.81 & & 0.87 & & \\
\hline Total & 0.80 & 0.82 & 0.87 & 0.85 & 0.03 \\
\hline \multicolumn{6}{|l|}{ Individual covariates } \\
\hline Age & 34.92 & 36.52 & 35.77 & 37.62 & -0.25 \\
\hline Female & 0.01 & 0.01 & 0.01 & 0.01 & 0.00 \\
\hline No vocational degree & 0.26 & 0.22 & 0.06 & 0.07 & -0.04 \\
\hline Secondary education & 0.65 & 0.73 & 0.89 & 0.91 & 0.06 \\
\hline Tertiary education & 0.00 & 0.00 & 0.00 & 0.00 & 0.00 \\
\hline Missing educational status & 0.08 & 0.04 & 0.04 & 0.02 & -0.02 \\
\hline Skilled workers & 0.61 & 0.64 & 0.83 & 0.81 & 0.04 \\
\hline Unskilled workers & 0.34 & 0.31 & 0.11 & 0.12 & -0.04 \\
\hline Master craftsman & 0.04 & 0.04 & 0.05 & 0.06 & 0.00 \\
\hline Part-time $<15$ hours/week & 0.00 & 0.00 & 0.00 & 0.00 & 0.00 \\
\hline Part-time $>15$ hours/week & 0.00 & 0.01 & 0.01 & 0.01 & 0.00 \\
\hline Prev. work exp. in sector (in years) & 2.03 & 10.69 & 2.12 & 8.12 & 2.65 \\
\hline Prev. tenure in firm (in years) & 1.88 & 8.64 & 2.06 & 9.62 & -0.80 \\
\hline \multicolumn{6}{|l|}{ Firm-level covariates } \\
\hline Share of skilled workers & 0.61 & 0.62 & 0.83 & 0.77 & 0.06 \\
\hline Share of unskilled workers & 0.34 & 0.30 & 0.11 & 0.12 & -0.05 \\
\hline Mean age of workforce & 35.00 & 36.88 & 35.77 & 38.07 & -0.42 \\
\hline 1-5 employees & 0.14 & 0.19 & 0.17 & 0.19 & 0.03 \\
\hline 6-10 employees & 0.26 & 0.27 & 0.19 & 0.20 & 0.01 \\
\hline $11-20$ employees & 0.31 & 0.30 & 0.22 & 0.22 & -0.01 \\
\hline$>20$ employees & 0.29 & 0.24 & 0.42 & 0.39 & -0.02 \\
\hline Mean daily gross wage in firms with $>2$ workers & 69.23 & 72.09 & 71.44 & 72.81 & 1.49 \\
\hline Number of observations & 125,334 & 375,344 & 137,444 & 471,454 & \\
\hline
\end{tabular}


E - Marginal effect of $D_{i t}$ in percentage points for placebo tests of approaches in Section 6.1 and 6.2

\begin{tabular}{|c|c|c|c|c|c|c|}
\hline & $\begin{array}{c}\text { Pooled } \\
\text { Logit }\end{array}$ & $\begin{array}{c}\text { Pooled } \\
\text { LPM }\end{array}$ & $\begin{array}{c}\text { Obs. } \\
\text { (in 1000) }\end{array}$ & $\begin{array}{l}\text { Pooled } \\
\text { Logit }\end{array}$ & $\begin{array}{c}\text { Pooled } \\
\text { LPM }\end{array}$ & $\begin{array}{c}\text { Obs. } \\
\text { (in 1000) }\end{array}$ \\
\hline & \multicolumn{3}{|c|}{ Eastern Germany } & \multicolumn{3}{|c|}{ Western Germany } \\
\hline \multicolumn{7}{|c|}{ Placebo tests for approach in Section 6.1 } \\
\hline 1994-95 with plumbers & 0.3 & 0.2 & 99 & $-1.7 * * *$ & $-1.7^{* * *}$ & 181 \\
\hline 1994-96 with plumbers & $-3.2^{* * *}$ & $-3.2^{* * *}$ & 150 & $0.6^{* *}$ & $0.8^{* *}$ & 267 \\
\hline \multicolumn{7}{|c|}{ Placebo tests for approach in Section 6.2} \\
\hline 1995-96, DiD BA data & $6.5^{* * *}$ & $5.2^{* * *}$ & 52 & -0.8 & -0.1 & 82 \\
\hline 1995-96, DiD LAK data & 1.9 & 1.0 & 66 & -3.3 & -2.0 & 109 \\
\hline
\end{tabular}

Note: Same specification as in Tables 4 and 6 with individual and firm-level controls; Significance levels: * $5 \%, * * 1 \%, * * * 0.1 \%$ 


\section{F - Mean difference between non-binding and binding workers of}

independent and dependent variables by sector prior to and after

\section{the MW introduction}

F.1 - Eastern Germany, BA data, 1994 - 2007

\begin{tabular}{|c|c|c|c|c|c|}
\hline & (1) & $(2)$ & (3) & $(4)$ & \multirow{2}{*}{$\begin{array}{c}\text { I } \\
\text { Unconditional } \\
\text { DiD }\end{array}$} \\
\hline & $\begin{array}{l}\text { before MW } \\
1995-1996\end{array}$ & $\begin{array}{c}\text { after MW } \\
1997-2007\end{array}$ & $\begin{array}{l}\text { before MW } \\
1995-1996\end{array}$ & $\begin{array}{l}\text { after MW } \\
1997-2007\end{array}$ & \\
\hline \multicolumn{6}{|c|}{ Dependent variable: Employed in the same sector in June of next year } \\
\hline 1995 & -0.25 & & -0.14 & & \\
\hline 1996 & -0.20 & & -0.14 & & \\
\hline Total & -0.22 & -0.10 & -0.14 & -0.07 & -0.05 \\
\hline \multicolumn{6}{|l|}{ Individual covariates } \\
\hline Age & -3.16 & -2.36 & -3.24 & -2.75 & -0.31 \\
\hline Female & 0.02 & 0.01 & 0.03 & 0.01 & -0.01 \\
\hline No vocational degree & 0.06 & 0.03 & 0.02 & 0.01 & 0.02 \\
\hline Secondary education & -0.05 & -0.01 & 0.02 & 0.02 & -0.03 \\
\hline Tertiary education & 0.00 & 0.00 & 0.00 & 0.00 & 0.00 \\
\hline Missing educational status & -0.01 & -0.02 & -0.04 & -0.03 & 0.02 \\
\hline Skilled workers & -0.17 & -0.05 & -0.06 & -0.01 & -0.06 \\
\hline Unskilled workers & 0.18 & 0.05 & 0.07 & 0.03 & 0.08 \\
\hline Master craftsman & -0.02 & -0.01 & -0.02 & -0.03 & -0.01 \\
\hline Part-time $<15$ hours/week & 0.00 & 0.00 & 0.00 & 0.00 & 0.00 \\
\hline Part-time $>15$ hours/week & 0.01 & 0.01 & 0.01 & 0.01 & -0.01 \\
\hline Prev. work exp. in sector (in years) & -0.86 & -0.75 & -0.61 & 0.32 & 0.83 \\
\hline Prev. tenure in firm (in years) & -0.83 & -1.68 & -0.43 & -0.99 & 0.28 \\
\hline \multicolumn{6}{|l|}{ Firm-level covariates } \\
\hline Share of skilled workers & 0.00 & 0.00 & -0.01 & -0.01 & -0.01 \\
\hline Share of unskilled workers & 0.00 & -0.02 & 0.01 & 0.00 & 0.02 \\
\hline Mean age of workforce & -0.66 & -0.05 & -0.85 & -0.41 & -0.16 \\
\hline 1-5 employees & 0.04 & 0.10 & 0.06 & 0.11 & -0.01 \\
\hline 6-10 employees & 0.03 & 0.03 & 0.00 & 0.03 & 0.03 \\
\hline 11-20 employees & 0.03 & -0.02 & -0.02 & -0.02 & 0.05 \\
\hline$>20$ employees & -0.10 & -0.11 & -0.04 & -0.12 & -0.07 \\
\hline Mean daily gross wage in firms with $>2$ workers & -9.00 & -5.87 & -9.55 & -8.64 & -2.22 \\
\hline Number of observations & 51,605 & 172,090 & 49,426 & 172,982 & | \\
\hline
\end{tabular}

F.2 - Western Germany, BA data, 1994 - 2007

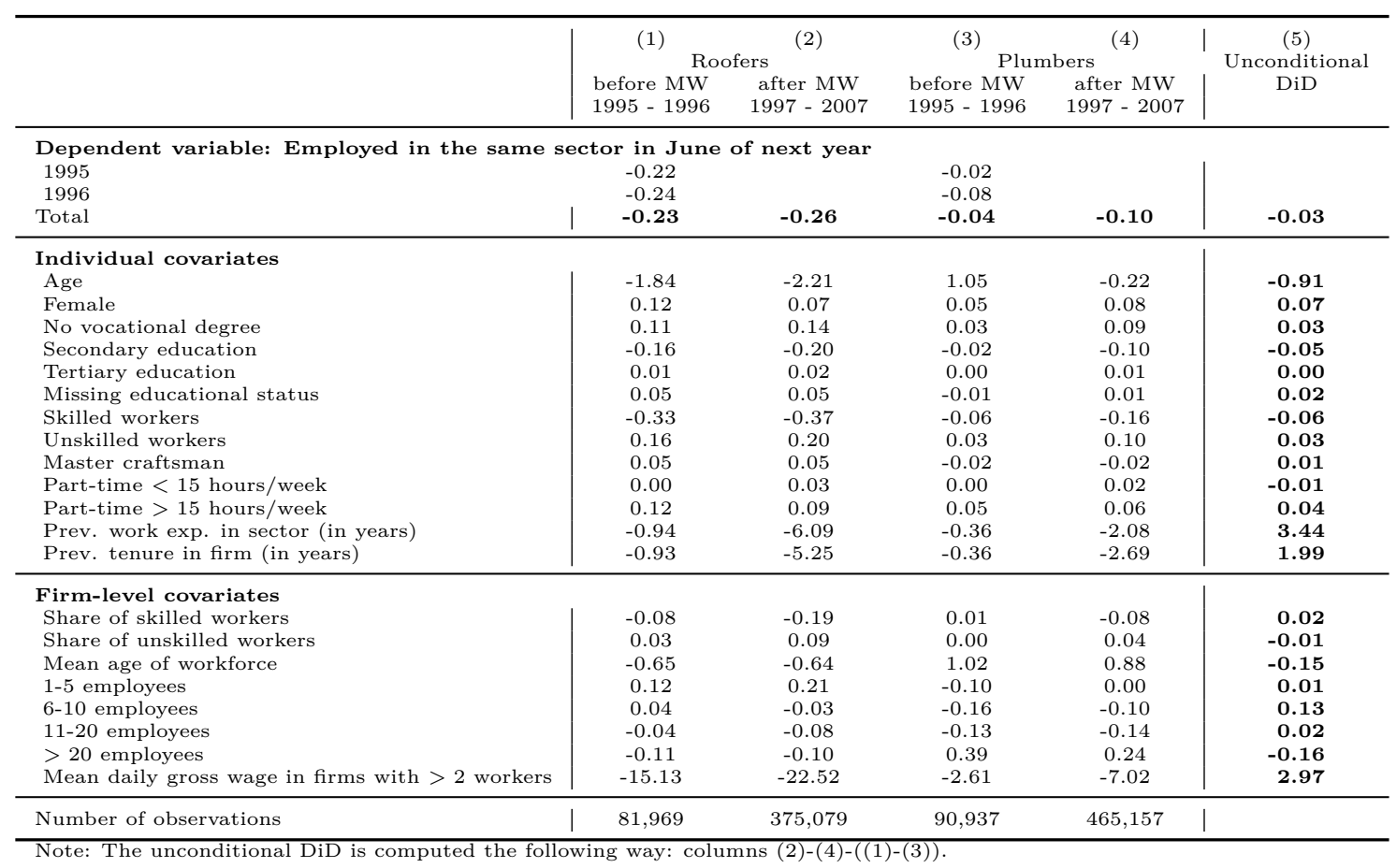


G - The probability of being affected by a binding MW, by sector and region, BA data, $1995-2007$

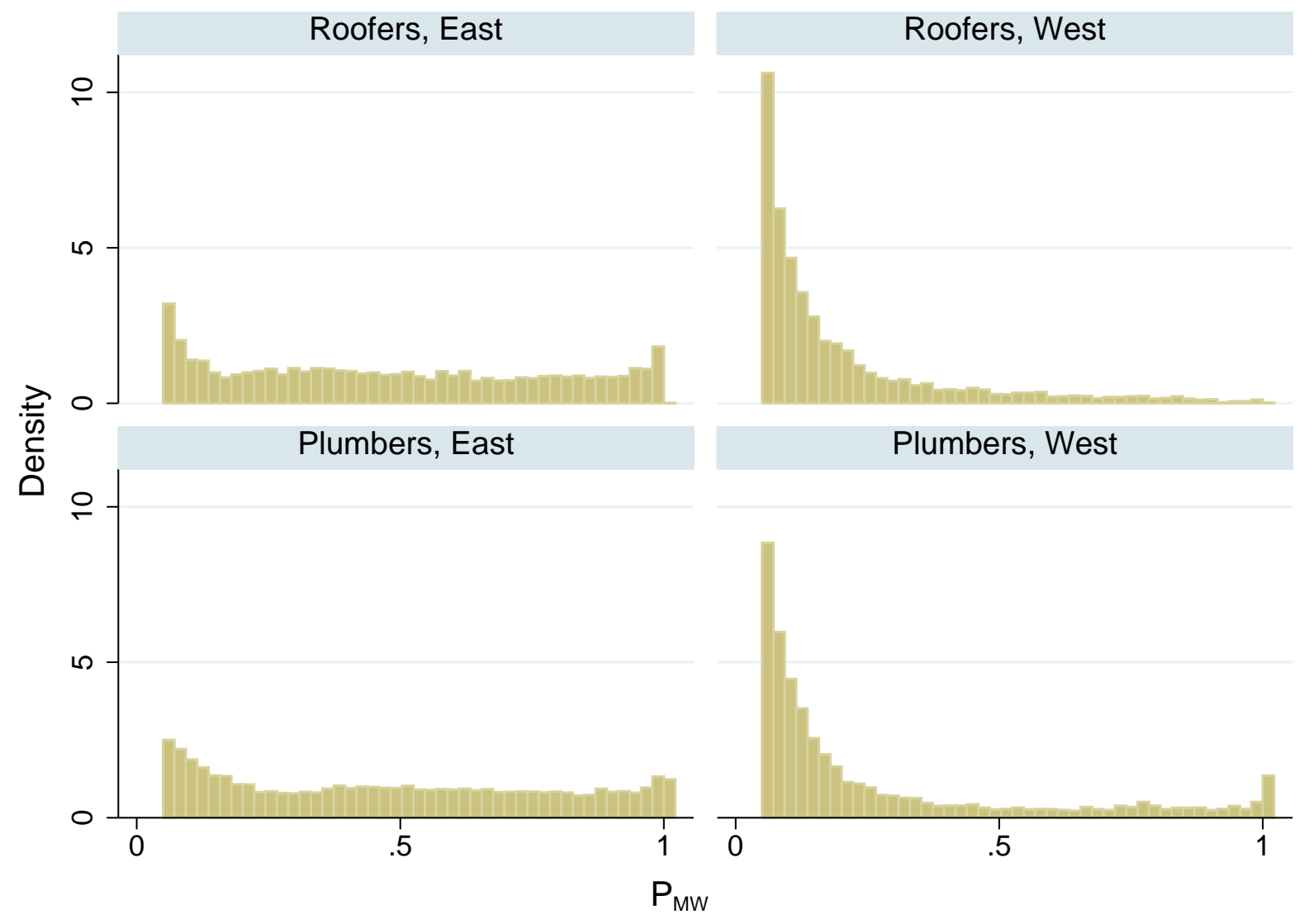


H - Probability of being affected by a binding $\mathbf{M W}\left(P_{M W}\right)$, by year, sector, and wage decile of the wage distribution in the roofing sector, BA data, 1995-2007

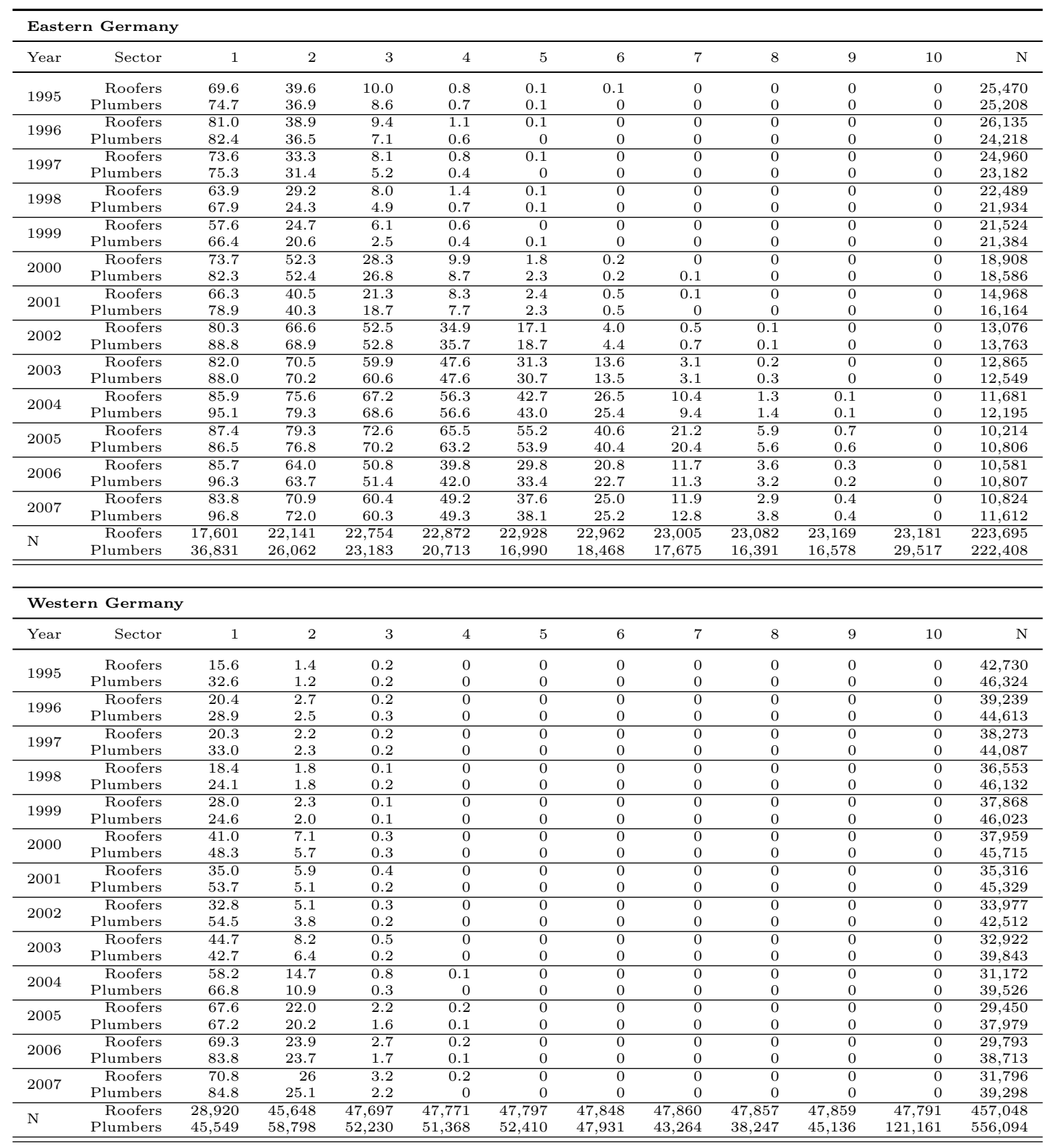

